\title{
Deficits in amygdaloid cAMP-responsive element-binding protein signaling play a role in genetic predisposition to anxiety and alcoholism
}

\author{
Subhash C. Pandey, Huaibo Zhang, Adip Roy, and Tiejun Xu
}

Department of Psychiatry, Psychiatric Institute, University of Illinois at Chicago, and Jesse Brown VA Medical Center, Chicago, Illinois, USA.

\begin{abstract}
We investigated the role of cAMP-responsive element-binding protein (CREB) in genetic predisposition to anxiety and alcohol-drinking behaviors using alcohol-preferring (P) and -nonpreferring (NP) rats. The levels of CREB, phosphorylated CREB, and neuropeptide $\mathrm{Y}$ (NPY) were innately lower in the central amygdala (CeA) and medial amygdala (MeA), but not in the basolateral amygdala (BLA), of P rats compared with NP rats. P rats displayed higher baseline anxiety-like behaviors and consumed higher amounts of alcohol compared with NP rats. Ethanol injection or voluntary intake reduced the higher anxiety levels in $P$ rats. Ethanol also increased CREB function in the CeA and MeA, but not in the BLA, of $P$ rats. Infusion of the PKA activator Sp-cAMP or NPY into the CeA decreased the alcohol intake and anxiety-like behaviors of $P$ rats. PKA activator infusion also increased CREB function in the CeA of $P$ rats. On the other hand, ethanol injection or voluntary intake did not produce any changes either in anxiety levels or on CREB function in the amygdaloid structures of NP rats. Interestingly, infusion of the PKA inhibitor Rp-cAMP into the CeA provoked anxiety-like behaviors and increased alcohol intake in NP rats. PKA inhibitor decreased CREB function in the CeA of NP rats. These novel results provide the first evidence to our knowledge that decreased CREB function in the CeA may be operative in maintaining the high anxiety and excessive alcohol-drinking behaviors of $P$ rats.
\end{abstract}

\section{Introduction}

Genetic factors are important in the predisposition to alcoholism (1-5). It has been suggested that some alcoholics may be predisposed to alcohol-drinking behaviors because of innately high anxiety levels (6-10). Animal lines such as alcohol-preferring (P) and -nonpreferring (NP) genetic rats appear to be suitable models to study the neurobiological basis of the genetic predisposition to anxiety and alcohol-drinking behaviors (11-14). It has been shown by some investigators $(15-17)$, but not all $(18,19)$, that $\mathrm{P}$ rats display higher anxiety-like behaviors than NP rats. Also, P rats orally self-administer higher amounts of ethanol for its positive-reinforcing action in the central nervous system, and ethanol consumption leads to the development of tolerance and dependence $(20,21)$. Although there are abnormalities in various neurotransmitter systems in the brain structures of P compared with NP rats $(13,14)$, the neuromechanism that may be responsible for the genetic vulnerability to higher anxiety levels and excessive alcohol-drinking behaviors of $\mathrm{P}$ rats is currently not well known.

The gene transcription factor cAMP-responsive element-binding protein (CREB) is the common denominator of the signaling cascades for a number of neurotransmitter receptors and is regulated

Nonstandard abbreviations used: aCSF, artificial CSF; BLA, basolateral amygdala; CeA, central amygdala; CRE, cAMP-responsive element; CREB, cAMP-responsive element-binding protein; CRF, corticotropin releasing factor; EPM, elevated plus maze; MeA, medial amygdala; NAc, nucleus accumbens; NP, alcohol-nonpreferring; NPY, neuropeptide Y; $\mathrm{P}^{-}$, phosphorylated; $\mathrm{P}$, alcohol-preferring; PKA-C $\alpha, \alpha$-catalytic subunit of PKA.

Conflict of interest: The authors have declared that no conflict of interest exists.

Citation for this article: J. Clin. Invest. 115:2762-2773 (2005).

doi:10.1172/JCI24381. via phosphorylation at serine 133 by cAMP-dependent PKA, $\mathrm{Ca}^{2+} /$ calmodulin-dependent protein kinases II and IV, and mitogenactivated protein kinase (22-24). Phosphorylated CREB (p-CREB) regulates the downstream expression of cAMP-inducible genes (25-27). Several prior studies indicate that CREB in the brain structures plays a role in alcohol dependence and preference (28-33). More specifically, it has been found that CREB-haplodeficient mice have a higher preference to alcohol (31). Also, it was found that the expression and phosphorylation of CREB and cAMP-responsive element-DNA (CRE-DNA) binding are lower in the whole amygdala of $P$ rats than NP rats (34). Neuropeptide Y (NPY) is one of several CREB-related target genes $(27,31,35)$ and has been shown to play a role in anxiety and alcohol abuse $(8,10,36-38)$. NPY-null mutant mice also display more anxiety-like behaviors and consume high amounts of alcohol $(38,39)$. The mRNA and protein levels of NPY are lower in the central amygdala (CeA) of P than of NP rats $(40,41)$. These previous studies suggest that CREB and NPY protein levels are lower in the amygdala of P compared with NP rats, but whether these deficiencies are directly regulating anxiety and alcohol-drinking behaviors of $\mathrm{P}$ rats is not yet known.

The CeA plays a crucial role in anxiety behaviors and also in promoting alcohol intake $(8,10,29,42-44)$. It is possible that $\mathrm{P}$ rats voluntarily drink excessive amounts of ethanol to reduce high anxiety levels, and this may also be associated with normalization of the decreased CREB and NPY levels in amygdaloid structures of P rats. We explored this possibility in the present investigation and examined the effects of ethanol exposure on anxiety-like behaviors and expression and phosphorylation of CREB, as well as expression of its target gene NPY, in the amygdaloid structures of $\mathrm{P}$ and NP rats. Since PKA regulates CREB phosphorylation $(22,25)$, we also examined 

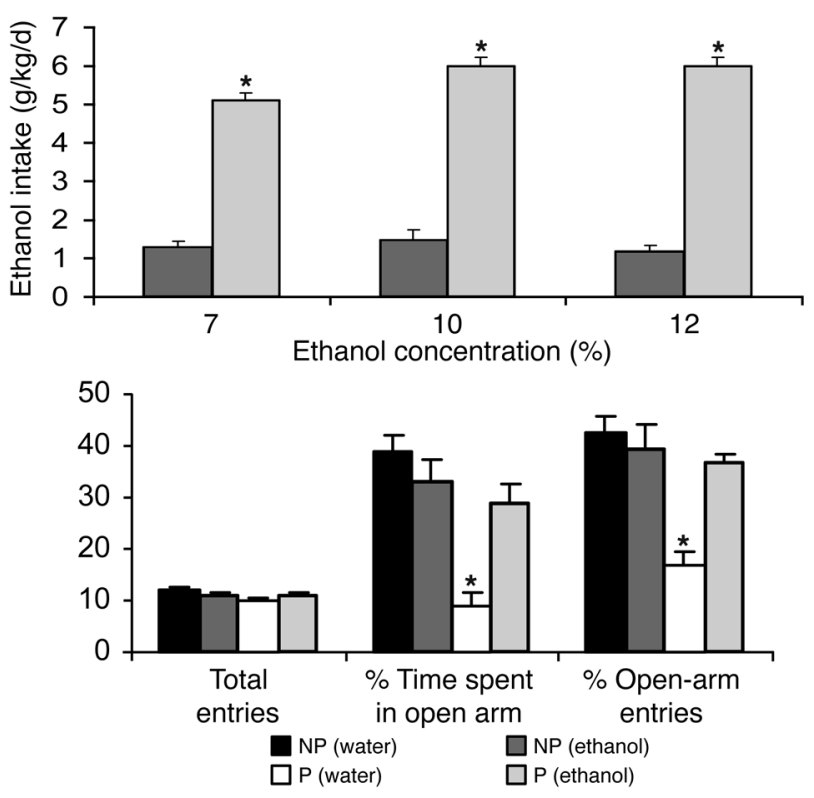

the effects of ethanol exposure on the protein levels of $\alpha$-catalytic subunit of PKA (PKA-C $\alpha$ ) in the amygdaloid structures of P and NP rats. To establish the role of the CeA CREB pathway in anxiety-like behaviors and alcohol-drinking behaviors using $\mathrm{P}$ and NP genetic rats as an animal model, we examined the effects of manipulations of the phosphorylation status of CREB on the expression of NPY in the $\mathrm{CeA}$ as well as on anxiety and alcohol-drinking behaviors. We also examined the effects of NPY infusion into the CeA on anxiety and alcohol-drinking behaviors of $\mathrm{P}$ rats. Since $\mathrm{P}$ and NP rats are selectively bred for high and low alcohol preference $(11,12,14)$, the data collected here provides the first evidence to our knowledge that lower $\mathrm{PKA} \rightarrow \mathrm{CREB} \rightarrow \mathrm{NPY}$ signaling in the CeA may be linked to higher anxiety and excessive alcohol-drinking behaviors of $\mathrm{P}$ rats.

\section{Results}

Baseline anxiety-like behaviors and baseline CREB and NPY levels in the brain structures of $P$ and $N P$ rats. The anxiety-like behaviors were measured in alcohol-naive $\mathrm{P}$ and NP rats using an elevated plus maze (EPM) test. P rats displayed higher levels of anxiety-like behaviors as demonstrated by the significantly lower percentage of openarm entries and percentage of time spent in open arms of the EPM compared with alcohol-naive NP rats. The overall general activity of $\mathrm{P}$ rats was similar to NP rats as there were no significant differences in total number of entries (open- plus closed-arm entries) between these rats (data not shown). These results suggest that $\mathrm{P}$ rats have higher levels of anxiety-like behaviors than NP rats.

After EPM testing, the basal protein levels of CREB, p-CREB, and NPY in the amygdaloid regions and nucleus accumbens (NAc) of P and NP rats were measured. It was found that total CREB, P-CREB, and NPY protein levels were significantly lower in the CeA and medial amygdala (MeA), but not in the basolateral amygdala (BLA), of $\mathrm{P}$ rats compared with NP rats. We also measured the basal NPY mRNA levels in the amygdaloid structures of $\mathrm{P}$ and NP rats. It was found that mRNA levels of NPY were lower in the CeA and MeA, but not in the BLA, of $\mathrm{P}$ compared with NP rats. On the other hand, the protein levels of CREB, p-CREB, and NPY were similar in the core and shell structures of NAc in P and NP rats (data not shown).

\section{Figure 1}

Alcohol-drinking patterns and anxiety-like behaviors in $\mathrm{P}$ and NP rats. Upper panel: Ethanol intake ( $7 \%$ for 3 days, $10 \%$ for 3 days, and $12 \%$ for 3 days) was measured by the 2-bottle free choice paradigm in $P$ and NP rats. Values represent the mean \pm SEM of 6 rats in each group. Lower panel: The effects of voluntary ethanol intake on openand closed-arm activities of $P$ and NP rats in the EPM test. Values represent the mean \pm SEM of $5-6$ rats in each group. ${ }^{*} P<0.001$ versus respective controls.

In 1 group of $\mathrm{P}$ and NP rats, we measured the CREB, $\mathrm{p}$-CREB, and NPY protein levels in amygdaloid structures without the EPM test. It was found that the EPM test had no effect on the levels of CREB, $\mathrm{P}-\mathrm{CREB}$, and NPY in the CeA, MeA, and BLA of $\mathrm{P}$ and NP rats (data not shown). These results suggest that CREB and NPY levels are innately lower in the CeA and MeA structures, but not in the BLA or NAc structures, of P rats compared with NP rats.

Effect of voluntary ethanol intake on anxiety-like behaviors in $P$ and NP rats. First, $\mathrm{P}$ and NP rats were habituated to drink water from 2 bottles. Once they started drinking water equally from both bottles, rats were given ethanol ( $7 \%$ for 3 days, $10 \%$ for 3 days, and $12 \%$ for 3 days) in 1 bottle. It was also found that $P$ rats drink more ethanol $(5-6 \mathrm{~g} / \mathrm{kg} / \mathrm{d})$ than NP rats $(1.2-1.5 \mathrm{~g} / \mathrm{kg} / \mathrm{d})$ under the 2-bottle choice paradigm (Figure 1, upper panel). These results confirm previous observations (11-13) and suggest that $P$ rats consume higher amounts of ethanol. On the morning of the tenth day, we measured the anxiety-like behaviors in these rats using the EPM test (Figure 1, lower panel). It was found that $\mathrm{P}$ rats displayed higher baseline anxiety-like behaviors, but these behaviors were normal in $\mathrm{P}$ rats exposed to ethanol (mean \pm SEM blood ethanol levels, $144 \pm 21 \mathrm{mg} / \mathrm{dl}$ at the time of brain collections; Figure 1, lower panel). These blood ethanol levels are within the range reported in the literature (14). The ethanol exposure (about $1.5 \mathrm{~g} / \mathrm{kg} / \mathrm{d}$ ) in NP rats (mean \pm SEM blood ethanol levels, $16.5 \pm 4.3 \mathrm{mg} / \mathrm{dl}$ at the time of brain collections) under the 2-bottle choice paradigm had no effects on the anxietylike behaviors. Ethanol exposure neither in P rats nor in NP rats had a significant effect on the general activity of the rats as measured by the total number of entries in the EPM (Figure 1, lower panel). These results suggest that $P$ rats display more anxiety-like behaviors, and voluntary ethanol intake produces anxiolytic effects in $P$ rats.

Effect of voluntary ethanol intake on CREB, p-CREB, PKA, and NPY levels in the amygdaloid structures of $P$ and $N P$ rats. Immediately after anxiety measurements, brains were collected to examine the effect of voluntary ethanol consumption on the protein levels of CREB and $\mathrm{p}$-CREB and the mRNA and protein levels of NPY in the amygdaloid structures of $\mathrm{P}$ and NP rats. We examined only amygdaloid structures because of basal differences in the levels of CREB and NPY in the amygdala but not in the NAc structures. The positive nuclei showing CREB and p-CREB gold immunolabeling are shown in Figure $2 \mathrm{~A}$. The cell bodies showing the mRNA and protein gold immunolabeling of NPY are shown in Figure 3A. It was found that ethanol exposure ( $7 \%$ for 3 days, $10 \%$ for 3 days, and $12 \%$ for 3 days) via the 2-bottle free choice paradigm (ethanol intake, about $6 \mathrm{~g} / \mathrm{kg} / \mathrm{d}$ ) led to increased phosphorylation of CREB (Figure 2) as well as increased expression of NPY (both mRNA and protein levels; Figure 3 ) in the $\mathrm{CeA}$ and $\mathrm{MeA}$, but not in the BLA, of P rats. Ethanol consumption had no significant effects on the protein levels of total CREB in the $\mathrm{CeA}, \mathrm{MeA}$, and BLA structures of $\mathrm{P}$ rats (Figure 2). The voluntary ethanol intake (about $1.5 \mathrm{~g} / \mathrm{kg} / \mathrm{d}$ ) in NP rats had no effect on CREB phosphorylation (Figure 2) or the expression of NPY (Figure 3) in 

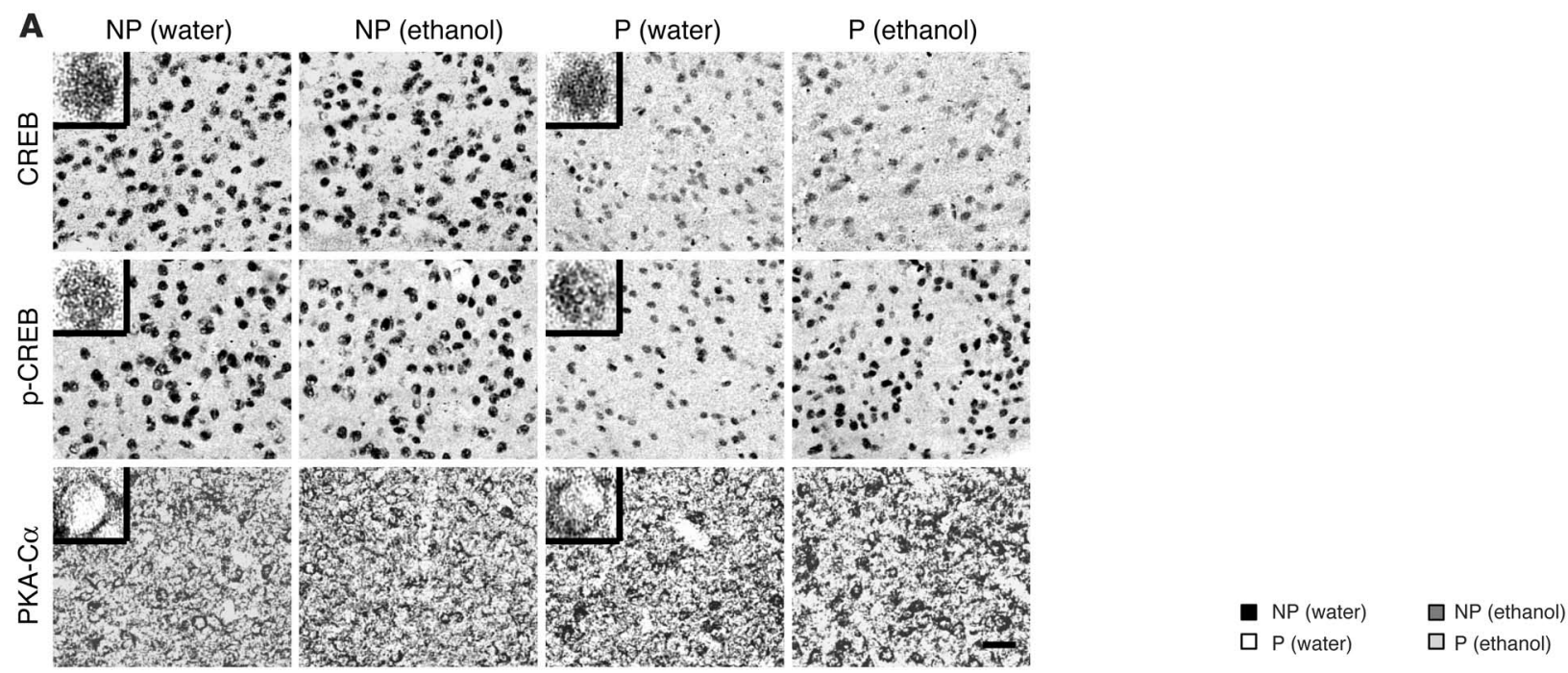

B
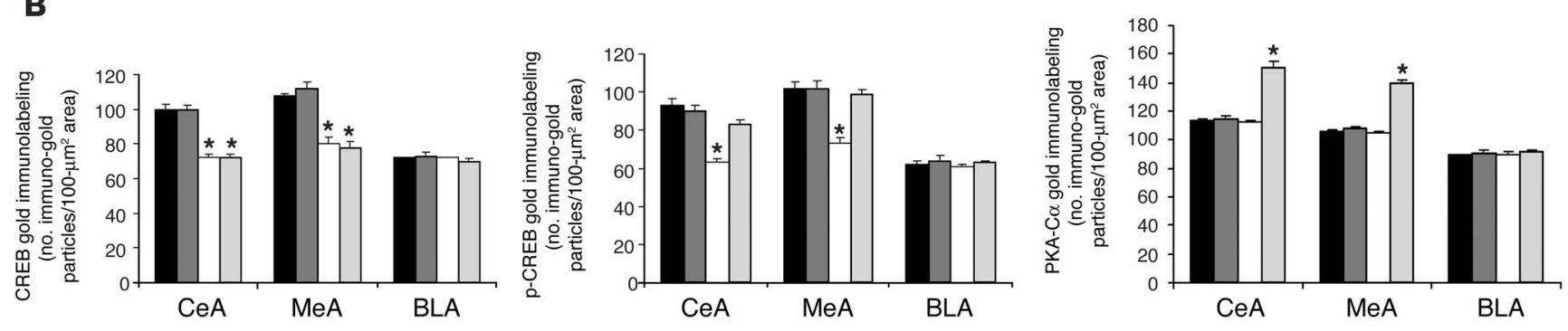

Figure 2

Voluntary ethanol intake and CREB signaling in the amygdala of $P$ and NP rats. (A) Low-magnification views of CREB, $p-C R E B$, and PKA-C $\alpha$ gold immunolabeling in $\mathrm{CeA}$ structures of $\mathrm{P}$ and NP rats with or without ethanol exposure. Photomicrographs show CREB-positive nuclei (upper panels), p-CREB-positive nuclei (middle panels), and PKA-C $\alpha$-positive cell bodies (lower panels) in the CeA of NP and P rats with or without ethanol exposure. Insets show the immuno-gold particles within a single nucleus (CREB and p-CREB) or cell body (PKA-C $\alpha$ ) at high magnification $(\times 100)$. Scale bar: $40 \mu \mathrm{m}$. (B) Effect of voluntary ethanol intake on CREB, p-CREB, and PKA-C $\alpha$ protein levels in various amygdaloid structures $(\mathrm{CeA}, \mathrm{MeA}$, and $\mathrm{BLA})$ of $\mathrm{P}$ and NP rats. Values represent the mean \pm SEM of $4-6$ rats in each group. ${ }^{*} P<0.001$ versus respective controls.

the amygdaloid structures. These results suggest that voluntary ethanol intake leads to increased CREB phosphorylation and NPY expression in the neural circuitry of $\mathrm{P}$ rat $\mathrm{CeA}$ and MeA.

In order to determine whether increased CREB phosphorylation in the $\mathrm{CeA}$ and $\mathrm{MeA}$ of $\mathrm{P}$ rats during ethanol exposure is related to increased protein levels of PKA-C $\alpha$ (active PKA), we examined the protein levels of PKA-C $\alpha$ in amygdaloid structures. The positive cell bodies containing PKA-C $\alpha$ proteins are shown in Figure 2A. It was found that voluntary ethanol intake (about $1.5 \mathrm{~g} / \mathrm{kg} / \mathrm{d}$ for 9 days) had no effect on the protein levels of PKA-C $\alpha$ in the CeA, MeA, or BLA of $\mathrm{NP}$ rats. On the other hand, voluntary ethanol intake (about $6 \mathrm{~g} / \mathrm{kg} / \mathrm{d}$ for 9 days) significantly increased the protein levels of PKA-C $\alpha$ in the $\mathrm{CeA}$ and $\mathrm{MeA}$, but not in the BLA, of P rats (Figure 2). These results suggest that increased $C R E B$ phosphorylation during ethanol consumption may be related to ethanol-induced increases in active PKA protein levels in the CeA and MeA of P rats.

Effect of acute ethanol injection on anxiety-like behaviors in $P$ and NP rats. Since NP rats drank less ethanol under the 2-bottle free choice paradigm, it is possible that differences between CREB phosphorylation and NPY levels in the CeA and MeA of P and NP rats during ethanol drinking could be related to differences in the amount of ethanol consumed. To explore this possibility, $\mathrm{P}$ and NP rats were injected i.p. with ethanol $(1 \mathrm{~g} / \mathrm{kg})$ or $\mathrm{n}$-saline, and after 1 hour of injection, anxiety-like behaviors in these rats were measured using the EPM test (Figure 4A). It was found that ethanol injection produced anxiolytic effects in $\mathrm{P}$ rats but not in NP rats. The blood ethanol levels were not significantly different between $P$ and NP rats (mean \pm SEM blood ethanol levels, $106 \pm 5 \mathrm{mg} / \mathrm{dl}$ in P and $112 \pm 22 \mathrm{mg} / \mathrm{dl}$ in NP rats at the time of brain collections). Acute ethanol exposure neither in $\mathrm{P}$ rats nor in NP rats had a significant effect on the general activity of the rats as measured by total number of entries in the EPM (Figure 4A). These results suggest that a similar amount of ethanol exposure produces anxiolytic effects in $\mathrm{P}$ but not in NP rats.

Effect of acute ethanol exposure on $p$-CREB, PKA, and NPY levels in the amygdaloid structures of $P$ and $N P$ rats. Immediately after anxiety measurements, brains were collected to examine the effect of acute ethanol injection $(1 \mathrm{~g} / \mathrm{kg})$ on the protein levels of $\mathrm{p}$-CREB, PKA-C $\alpha$, and NPY in the amygdaloid structures of P and NP rats. It was found that acute ethanol exposure significantly increased protein levels of PKA-C $\alpha, \mathrm{p}-\mathrm{CREB}$, and NPY in the CeA and MeA, but not in the BLA, of $P$ rats. On the other hand, a similar amount of ethanol injection had no effect on the protein levels of PKA-C $\alpha$, $\mathrm{p}-\mathrm{CREB}$, and NPY in the CeA, MeA, and BLA structures of NP rats (Figure $4 \mathrm{~B}$ ). These results suggest that the function of the PKA $\rightarrow$ $\mathrm{CREB} \rightarrow \mathrm{NPY}$ system is increased in the CeA and MeA of $\mathrm{P}$ but not NP rats due to ethanol exposure. 

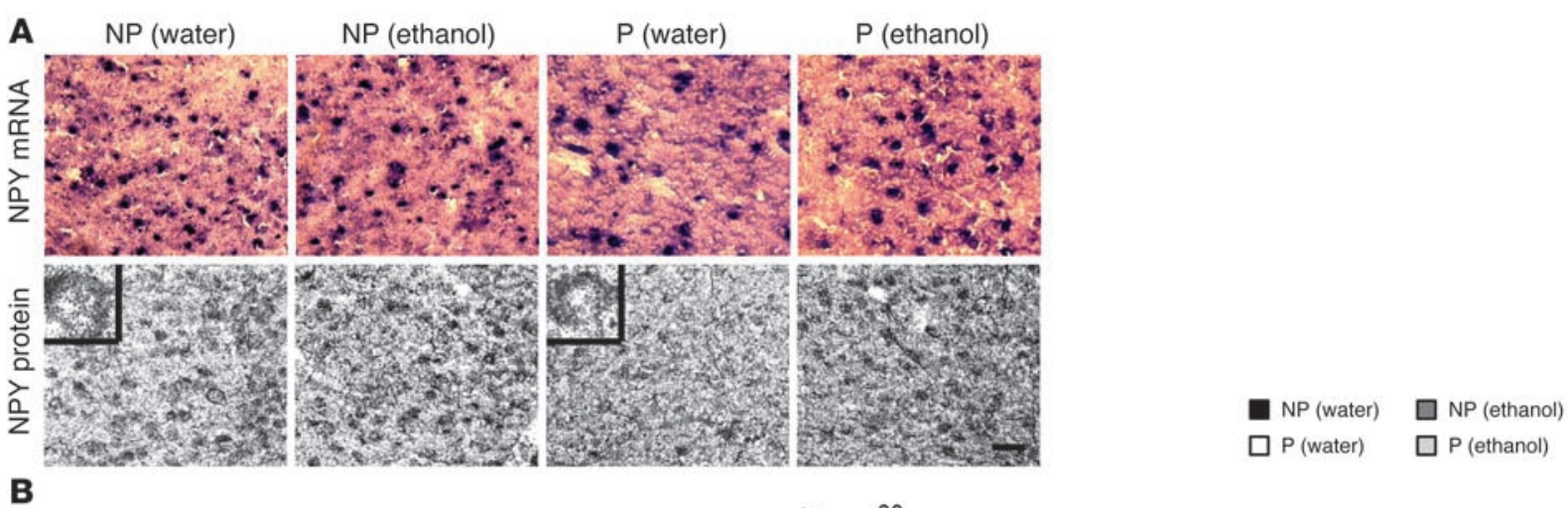

B

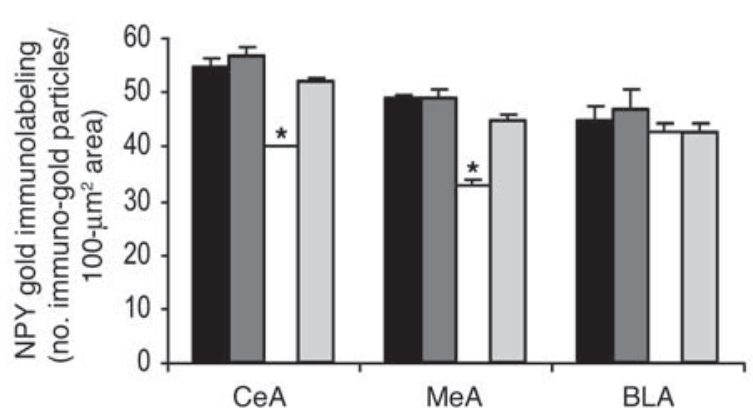

Figure 3

Voluntary ethanol intake and NPY levels in the amygdala of P and NP rats. (A) Low-magnification views of NPY mRNA expression (in situ RT-PCR; upper panels) and NPY gold immunolabeling (lower panels) in the CeA of NP and P rats with or without ethanol exposure. Insets show the immuno-gold particles in a cell body at high magnification $(\times 100)$. Scale bar: $40 \mu \mathrm{m}$. (B) Effects of voluntary ethanol intake on mRNA and protein levels of NPY in the CeA, MeA, and BLA structures of NP and P rats. Values represent the mean \pm SEM of 4-6 rats in each group. ${ }^{*} P<0.001$ versus respective controls.

Effect of PKA activator infusion into the CeA on anxiety and alcohol preference as well as on CREB signaling in $P$ rats. We observed that $P$ rats, when drinking ethanol, displayed lower anxiety-like behaviors and had higher protein levels of PKA-C $\alpha$ and increased CREB phosphorylation and NPY expression in the CeA and MeA but not in the BLA. These results suggest that $P$ rats drink more ethanol in order to increase active PKA and normalize the deficit in CREB phosphorylation and thereby NPY expression in these structures of amygdala. To test this possibility, we infused the PKA activator Sp-cAMP directly into the CeA (Figure 5) and examined its effects on alcohol intake, anxiety levels, CREB phosphorylation, and NPY expression in the amygdaloid structures. P rats were habituated to drink water from 2 bottles and then were given 7\% ethanol for 3 days followed by $9 \%$ ethanol for 6 days. Once P rats had been drinking 9\% ethanol for 3 days, they were infused once (within a 2 -minute period) daily for 3 days (between 5 and $6 \mathrm{pm}$ on the fourth, fifth, and sixth days of $9 \%$ ethanol intake) with $0.5 \mu \mathrm{l}$ of artificial CSF (aCSF) or $0.5 \mu \mathrm{l}$ of $80 \mathrm{nmol}$ of Sp-cAMP. It was found that infusions of PKA activator into the CeA significantly decreased the alcohol intake in $\mathrm{P}$ rats (Figure 6, upper panel) without changing total fluid intake. On the morning of the tenth day (after 9 days of ethanol intake, $7 \%$ for 3 days and $9 \%$ for 6 days), we measured anxiety-like behaviors in these rats. It was found that PKA activator and ethanol intake alone produced a significant increase in open-arm activity (entries and percent time spent on open arms) of P rats on the EPM test (Figure 6, lower panel). Interestingly, when PKA activator was specifically infused into the CeA, P rats drank less alcohol and were not anxious (Figure 6, lower panel). These results suggest that PKA activator infusion into the $\mathrm{CeA}$ of $\mathrm{P}$ rats decreases the anxiety levels and alcohol intake.
Immediately after measuring anxiety, brains were collected to examine the cellular expression of PKA-C $\alpha$, CREB, p-CREB, and NPY in P rats - with or without alcohol drinking - that were infused with Sp-cAMP or aCSF. Figure 7A shows the positive cell bodies containing PKA-C $\alpha$ (upper panel) and nuclei containing CREB (middle panel) and p-CREB (lower panel) proteins in the $\mathrm{CeA}$. The positive cell bodies containing protein and mRNA of NPY are shown in Figure 8A. It was found that PKA activator infusion into the CeA increased the protein levels of PKA-C $\alpha$ and p-CREB (Figure 7) and NPY expression (both mRNA and protein levels; Figure 8) in the CeA, but not in the MeA or BLA, of P rats. On the other hand, alcohol consumption with or without PKA activator infusion into the CeA increased protein levels of PKA-C $\alpha$, CREB phosphorylation, and NPY expression (both mRNA and protein levels) in the CeA and MeA, but not in the BLA, of $\mathrm{P}$ rats. In the $\mathrm{MeA}$ of $\mathrm{P}$ rats, these increases were related to ethanol exposure. Neither alcohol exposure nor PKA activator infusion into the CeA had any effect on total CREB protein levels in amygdaloid structures of $\mathrm{P}$ rats (Figure 7 ). It was also found that PKA activator infusion did not cause any toxicity in the CeA of $\mathrm{P}$ rats, as demonstrated by Nissl staining (Figure 5). These results suggest that normalization of decreased CREB phosphorylation, specifically in the CeA via activation of PKA, attenuates high anxiety levels and higher alcohol intake in $P$ rats.

Effect of NPY infusion into the CeA on anxiety and alcohol intake in $P$ rats. PKA activator decreased anxiety levels and alcohol intake in $P$ rats and increased protein levels of PKA-C $\alpha$ and P-CREB and NPY levels in the CeA, but not in the MeA and BLA. These results suggest the possibility that $\mathrm{CREB}$ in the $\mathrm{CeA}$ of $\mathrm{P}$ rats may regulate 
A

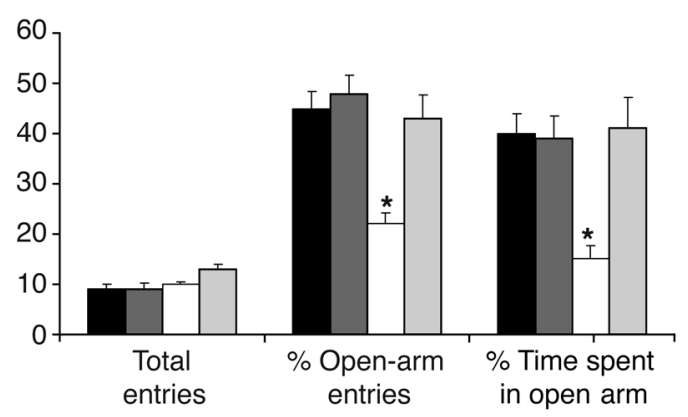

B

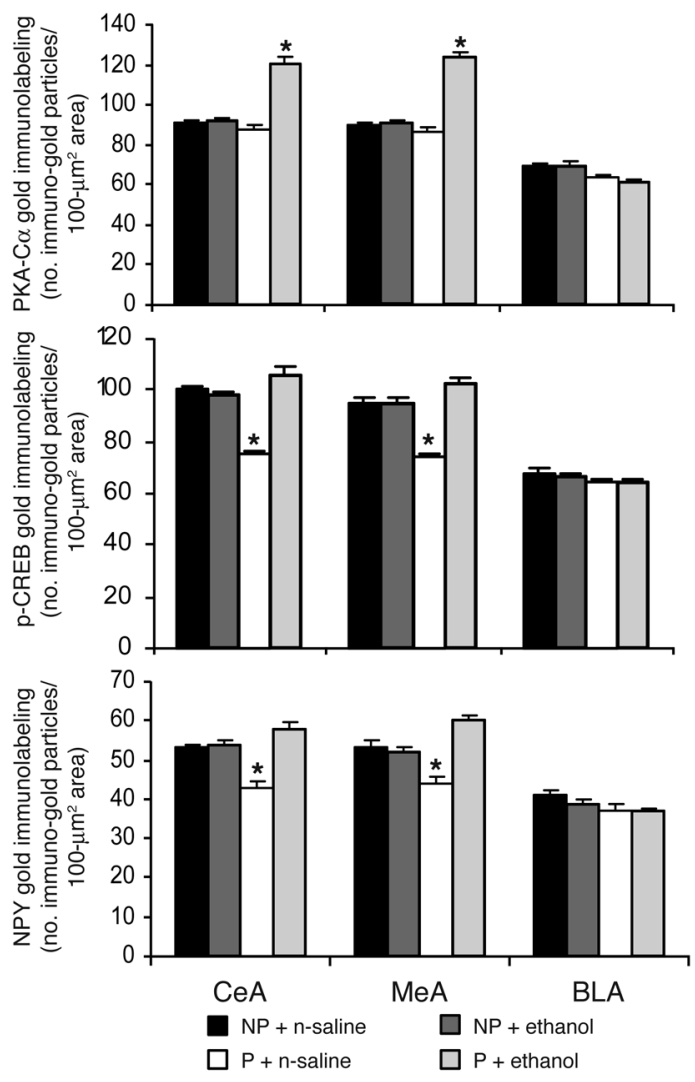

anxiety and alcohol-drinking behaviors via NPY. To test this possibility, we infused NPY directly into the CeA and examined the effects on alcohol intake and anxiety levels. P rats were habituated to drink water from 2 bottles and then were given $7 \%$ ethanol for 3 days followed by $9 \%$ ethanol for 6 days. Once P rats were drinking $9 \%$ ethanol for 3 days, they were infused once (within a 2-minute period) daily for 3 days (between 5 and $6 \mathrm{pm}$ on the fourth, fifth, and sixth days of $9 \%$ ethanol intake) with $0.5 \mu \mathrm{l}$ of aCSF or $0.5 \mu \mathrm{l}$ of $100 \mathrm{pmol}$ of NPY. It was found that infusions of NPY into the CeA significantly decreased the alcohol intake in P rats (Figure 9, upper panel) without changing total fluid intake. On the morning of the tenth day (after 9 days of ethanol intake, $7 \%$ for 3 days and $9 \%$ for 6 days), we measured anxiety-like behaviors in these rats. It was found that NPY and ethanol intake alone produced a significant increase in open-arm activity (entries and percent time spent on open arms) of P rats on the EPM test (Figure 9, lower panel). Interestingly, when NPY was specifically infused into the CeA, P rats

\section{Figure 4}

Anxiety-like behaviors and CREB function in the amygdala of $P$ and NP rats following acute ethanol exposure. (A) The effects of acute ethanol injection (i.p.) on open- and closed-arm activities of $P$ and NP rats in the EPM test. Values represent the mean \pm SEM of $5-7$ rats in each group. (B) Effect of acute ethanol exposure on p-CREB, PKA-C $\alpha$, and NPY protein levels in various amygdaloid structures (CeA, MeA, and $B L A)$ of $P$ and NP rats. Values represent the mean \pm SEM of 5 rats in each group. ${ }^{*} P<0.001$ versus respective controls.

drank less alcohol and were not anxious (Figure 9, lower panel). These results suggest that NPY infusion into the CeA decreases anxiety levels and alcohol intake in $P$ rats.

Effect of PKA inbibitor infusion into the CeA on anxiety and alcohol preference as well as on CREB signaling in $N P$ rats. If $\mathrm{P}$ rats have higher anxiety-like behaviors and alcohol preference due to lower CREB phosphorylation and lower NPY levels in the CeA, then decreasing CREB phosphorylation and NPY expression in the CeA of NP rats should provoke anxiety-like behaviors and higher alcohol intake in NP rats. To test this possibility, we infused the PKA inhibitor Rp-cAMP into the CeA and examined the effects on alcohol intake, anxiety levels, CREB phosphorylation, and NPY expression in the amygdaloid structures of NP rats. NP rats were habituated to drink water from 2 bottles and then were given 7\% ethanol for 3 days followed by $9 \%$ ethanol for 6 days as described above for P rats. Once NP rats were drinking $9 \%$ ethanol for 3 days, they were infused once (within a 2-minute period) daily for 3 days (between 5 and 6 $\mathrm{pm}$ on the fourth, fifth, and sixth days of $9 \%$ ethanol intake) with $0.5 \mu \mathrm{l}$ of aCSF or $0.5 \mu \mathrm{l}$ of $40 \mathrm{nmol}$ of Rp-cAMP. It was found that infusions of PKA inhibitor into the CeA significantly increased the alcohol intake in NP rats (Figure 10, upper panel) without changing total fluid intake. On the morning of the tenth day (after 9 days of ethanol intake, $7 \%$ for 3 days and 9\% for 6 days), we measured anxiety-like behaviors in NP rats. It was found that PKA inhibitor alone produced a significant decrease in open-arm activity (entries and percent time spent on open arms) of NP rats on the EPM test. Interestingly, when PKA inhibitor was infused into the CeA, NP rats drank higher amounts of alcohol, which normalized PKA inhibitor-induced anxiety-like behaviors (Figure 10, lower panel). These results suggest that PKA inhibitor infusion into the CeA increases anxiety levels and alcohol intake in NP rats.

Immediately after measuring anxiety, brains were collected to examine the cellular expression of PKA-C $\alpha$, CREB, p-CREB, and NPY protein levels in NP rats - with or without alcohol drinking - infused with Rp-cAMP or aCSF. Figure 11A shows the positive cell bodies containing PKA-C $\alpha$ (upper panels) and nuclei containing CREB (middle panels) and p-CREB (lower panels) in the $\mathrm{CeA}$. The positive cell bodies containing protein and mRNA of NPY are shown in Figure 12A. It was found that PKA inhibitor infusion into the CeA decreased the protein levels of PKA-C $\alpha$ and CREB phosphorylation (Figure 11B) as well as NPY expression (both mRNA and protein levels; Figure 12B) in the CeA, but not in the MeA or BLA, of NP rats. On the other hand, alcohol intake induced after infusion of PKA inhibitor in the CeA normalized the PKA-C $\alpha$ protein levels, CREB phosphorylation, and NPY expression (both mRNA and protein levels; Figure 11B and Figure 12B) in the CeA of NP rats. Voluntary ethanol intake or PKA inhibitor infusion into the CeA did not have any effect on total CREB protein levels in amygdaloid structures of NP rats (Figure 11B). It was also found that PKA inhibitor infusion did 


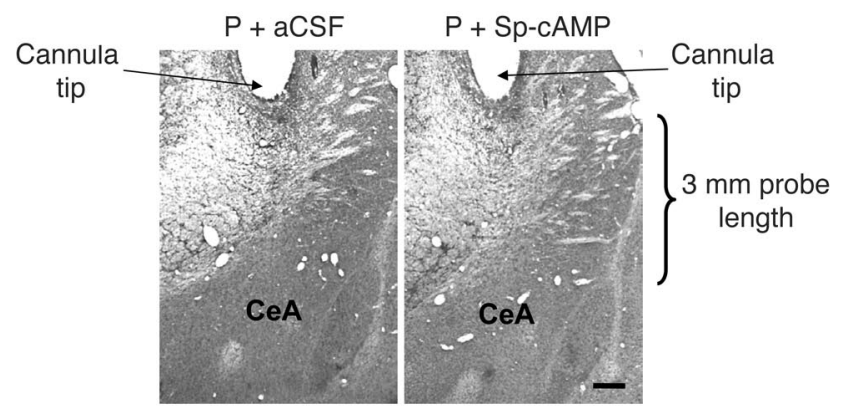

Figure 5

Low-magnification views of Nissl staining of brain sections showing the positions of cannula tips, probe lengths, and $\mathrm{CeA}$ target regions of $\mathrm{P}$ rats infused with aCSF or Sp-cAMP. Scale bar: $250 \mu \mathrm{m}$.

not cause any toxicity in the CeA of NP rats, as demonstrated by Nissl staining (data not shown). These results suggest that decreased CREB phosphorylation and NPY expression, specifically in the CeA structures via inhibition of PKA, provokes high anxiety levels and increases alcohol intake in NP rats.

\section{Discussion}

The present investigation identifies a novel molecular mechanism in the neural circuitry of the CeA of P rats, which suggests that decreased CREB phosphorylation-dependent NPY expression may be involved in genetic predisposition to anxiety and alcohol-drinking behaviors. This work also provides evidence for the first time to our knowledge that ethanol exposure attenuates higher anxiety levels; this is associated with ethanol-induced increases in PKA-dependent CREB phosphorylation and NPY expression (both mRNA and protein levels) in the CeA and MeA of $\mathrm{P}$ rats. Furthermore, the present work also provides evidence that decreasing CREB phosphorylation-dependent NPY expression in the CeA of NP rats provokes anxiety-like behaviors and promotes alcohol intake. In other words, increasing the CREB phosphorylation-dependent NPY expression in the CeA of P rats decreases anxiety levels and attenuates alcohol intake, whereas decreasing the CREB phosphorylation-dependent NPY expression in the CeA of NP rats increases anxiety levels and alcohol preference. Therefore, turning off the PKA-dependent CREB phosphorylation in the CeA of NP rats makes these rats like $\mathrm{P}$ rats in terms of anxiety and alcohol-drinking phenotypes.

Several lines of evidence indicate that CREB phosphorylation at serine 133 plays a crucial role in synaptic plasticity associated with learning and memory and addictive behaviors (45-47). The CeA and MeA, along with shell structures of NAc, represent important circuitries of the extended amygdala, which has been shown to be involved in the rewarding, reinforcing, and motivating aspects of alcohol-drinking behaviors $(8,29,42)$. Here, we found that protein levels of CREB and $\mathrm{p}-\mathrm{CREB}$ were innately lower in the CeA and MeA, but not in the BLA and shell and core structures of NAc, of P compared with NP rats. The basal protein levels of PKA-C $\alpha$ were similar in the amygdaloid structures of $\mathrm{P}$ and NP rats. We reported earlier that CRE-DNA binding was lower in the nuclear extracts of whole amygdala, but not in the cortex, striatum, or hippocampus, of P compared with NP rats (34). These results suggest that there are innately lower protein levels of CREB and $\mathrm{p}$-CREB in the amygdaloid, but not in the NAc, structures of P rats compared with NP rats.
When CREB becomes active after phosphorylation, it is able to regulate the expression of CREB target genes, and NPY is one of them $(27,31,35)$. Interestingly, here we also found that NPY expression is lower in the CeA and MeA, but not in the BLA or the core and shell structures of NAc, of P compared with NP rats. Behaviorally, we found that $\mathrm{P}$ rats displayed more anxiety-like behaviors and consumed higher amounts of alcohol compared with NP rats. Several previous reports support these behavioral findings and findings of NPY levels in the CeA of P rats (15-17, 39-41). Next, an obvious question arises: does decreased CREB function in the amygdala regulate anxiety and excessive alcoholdrinking behaviors of $\mathrm{P}$ rats?

Studies conducted in animal models and human alcoholics suggest that there is a relationship between high anxiety levels and alcohol consumption $(7,9,15,16,48-50)$. It is possible that $P$ rats may drink excessive amounts of alcohol because of higher anxiety levels, and ethanol may also be able to normalize the reduction in CREB phosphorylation and NPY expression in the $\mathrm{CeA}$ and MeA. When exposed to alcohol (via 2-bottle free choice or injection), we found that $\mathrm{P}$ rats did not display high anxiety levels; additionally, CREB phosphorylation and NPY expression were increased in the $\mathrm{P}$ rats' CeA and MeA, but not in their BLA. The increase in CREB phosphorylation was related to an increase in PKA-C $\alpha$ protein levels in the CeA and MeA of $\mathrm{P}$ rats. Previous studies indicate that ethanol has properties to elevate the PKA-C $\alpha$ protein levels in the nuclei of culture cells $(51,52)$. In the present study, we also found that NP rats drank less alco-
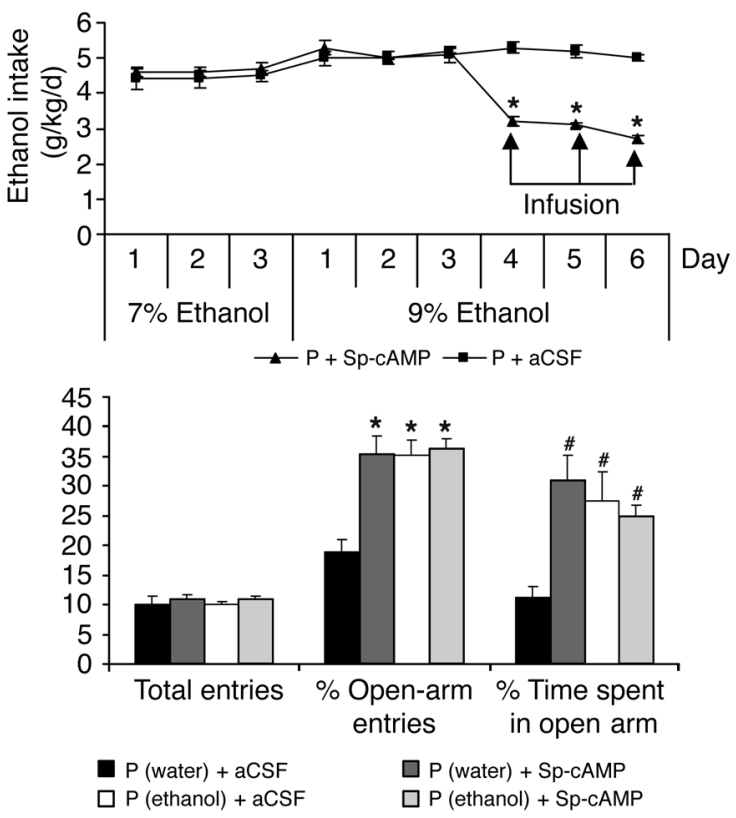

\section{Figure 6}

The effect of PKA activator infusion into the CeA on ethanol intake and anxiety-like behaviors in $\mathrm{P}$ rats. Upper panel: The alcohol-drinking patterns (7 and 9\% ethanol) and the effect of Sp-cAMP infusion into the $\mathrm{CeA}$ on alcohol intake (last 3 days of $9 \%$ ethanol intake) in $\mathrm{P}$ rats. Values represent the mean \pm SEM of $5-6$ rats in each group. Lower panel: The effect of PKA activator infusion $(0.5 \mu \mathrm{l}$ of $80 \mathrm{nmol}$ of Sp-cAMP or aCSF once daily for 3 days) and ethanol exposure on open- and closed-arm activities of $P$ rats in the EPM. Values represent the mean \pm SEM of $5-6$ rats in each group. ${ }^{\#} P<0.01,{ }^{*} P<0.001$ versus $P$ rats infused with aCSF. 


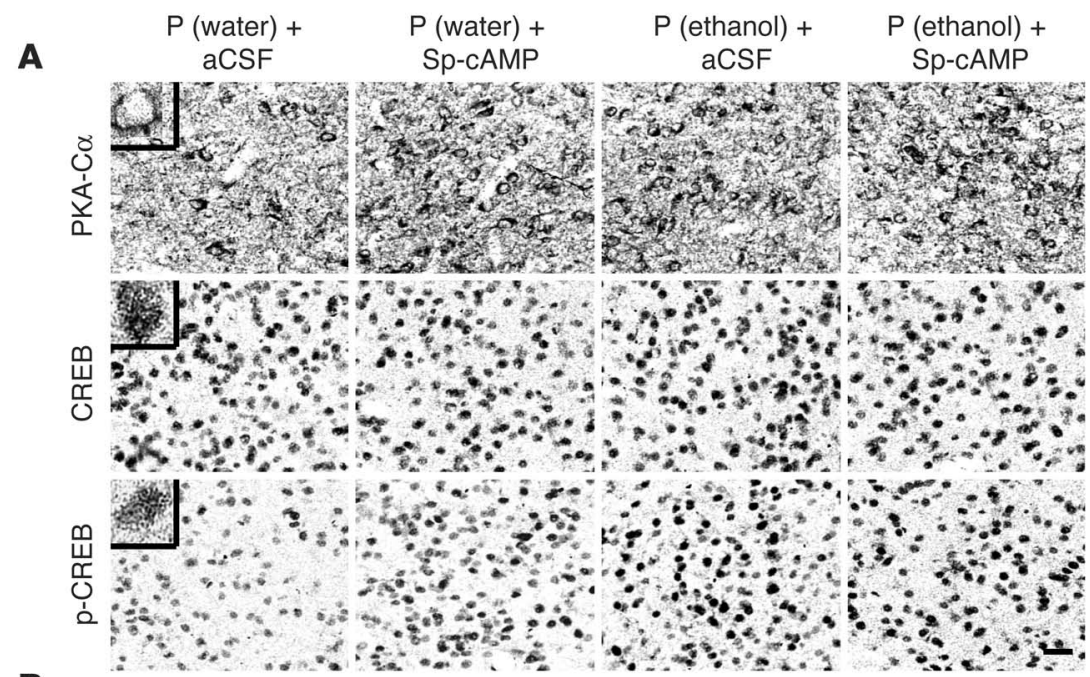

D $($ water $)+$ aCSF $\square P($ water $)+$ Sp-cAMP $\square \mathrm{P}($ ethanol $)+\mathrm{aCSF} \square \mathrm{P}($ ethanol $)+\mathrm{Sp}$-cAMP
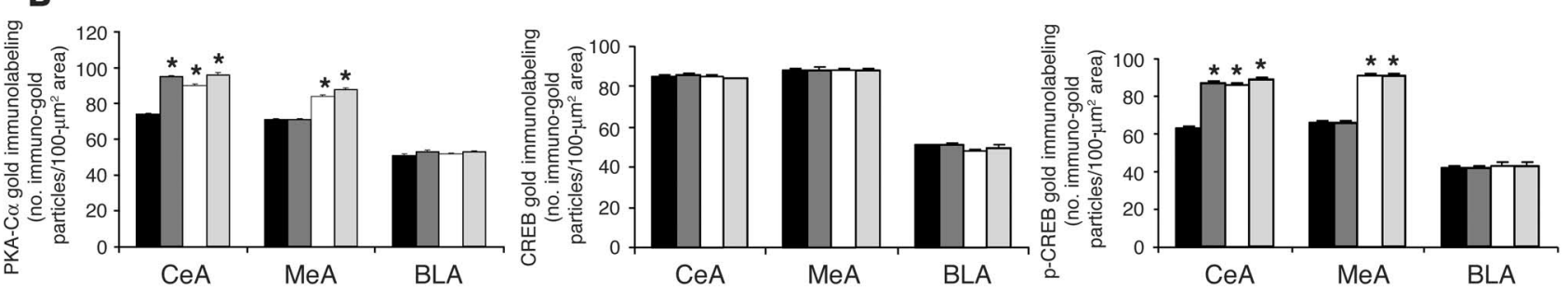

Figure 7

PKA activator infusion into the CeA during ethanol intake and CREB signaling in the amygdala of $P$ rats. (A) Low-magnification views of PKA-C $\alpha$, CREB, and $p$-CREB gold immunolabeling in the CeA of $P$ rats infused with or without Sp-cAMP during ethanol exposure. Photomicrographs show PKA-C $\alpha$-positive cell bodies or CREB- and p-CREB-positive nuclei in the CeA of P rats infused with aCSF or PKA activator. Insets show the immuno-gold particles within a single nucleus (CREB and p-CREB) or cell body (PKA-C $\alpha$ ) at high magnification $(\times 100)$. Scale bar: $40 \mu \mathrm{m}$. (B) Effect of Sp-cAMP infusion into the CeA and voluntary ethanol exposure on PKA-C $\alpha$, CREB, and $p$-CREB protein levels in amygdaloid structures of $P$ rats. Values represent the mean \pm SEM of $5-6$ rats in each group. ${ }^{*} P<0.001$ versus $P$ rats infused with aCSF.

hol, and exposure to low amounts of ethanol - or exposure to similar amounts of ethanol as $P$ rats via acute injection - did not have any effect on anxiety levels or levels of PKA-C $\alpha$, p-CREB, and NPY in their amygdaloid structures. These results suggest that decreased CREB phosphorylation in the CeA and MeA may be responsible for predisposition to anxiety and alcohol-drinking behaviors in P rats and that ethanol exposure increases the PKAdependent CREB phosphorylation and thereby NPY expression in the CeA and MeA of $\mathrm{P}$ but not of NP rats.

As mentioned above, if $\mathrm{P}$ rats drink ethanol to increase active PKA levels, CREB phosphorylation, and NPY expression in the $\mathrm{CeA}$ and MeA structures and to ameliorate anxiety-like behavior, then infusion of PKA activator or NPY into the CeA should attenuate anxiety and decrease alcohol intake. Here we report that PKA activator infusion into the CeA of $\mathrm{P}$ rats significantly decreased alcohol intake and also attenuated the anxiety-like behaviors in these rats. PKA activator infusion also significantly increased CREB phosphorylation and NPY expression in P rats by increasing the PKA-C $\alpha$ protein levels specifically in the CeA. Interestingly, it was also found that NPY infusion into the CeA significantly attenuated the anxiety levels and alcohol intake in $\mathrm{P}$ rats. Previous studies also support the relationship between decreased CREB and NPY levels and anxiety and alcohol-drinking behaviors $(15,16$, 36-41). It has been shown that icv infusions of NPY significantly attenuate the alcohol intake in $\mathrm{P}$ rats (53), but not in an unselected stock of rats (54). We reported earlier that CREB-haplodeficient mice have lower levels of NPY throughout the brain, display higher anxiety-like behaviors, and also have higher preference for alcohol (31). Other investigators have shown that decreased CREB may be involved in anxiety-like behaviors $(29,55,56)$. We also reported earlier that decreased CREB phosphorylation and NPY expression in the CeA might be involved in anxiety-like behaviors during ethanol withdrawal in an unselected stock of rats $(30,57)$. However, the current studies are novel in that they specify that decreased CREBdependent NPY function in the neural circuitry of CeA may be a pre-existing condition for anxiety and alcohol-drinking behaviors and plays a role in the association of anxiety and alcohol-drinking behaviors in $\mathrm{P}$ rats (Figure 13).

We also tested the possibility that NP rats are not anxious and drink less alcohol, which may be due to the fact that they have normal levels of CREB, p-CREB, and NPY expression in the CeA and $\mathrm{MeA}$. The effects of PKA inhibitor infusion into the CeA on anxiety and alcohol-drinking behaviors of NP rats were examined. Here we report that NP rats initially drank less alcohol, but when they were infused with PKA inhibitor into the CeA, their alcohol intake was significantly increased, and they also displayed higher levels of anxiety as compared with aCSF-infused NP rats. The NP rats infused with PKA inhibitor had lower levels of PKA-C $\alpha, \mathrm{p}-\mathrm{CREB}$, and NPY expression, specifically in the CeA. Interestingly, PKA inhibitor-infused NP rats drank more ethanol, which led to nor- 


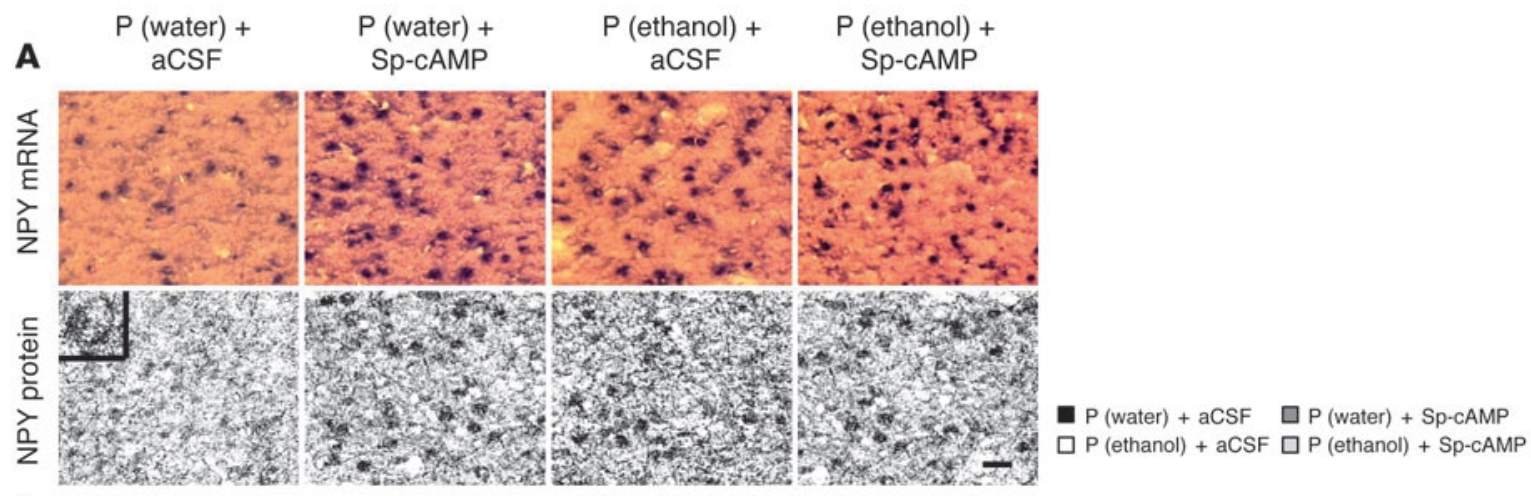

B
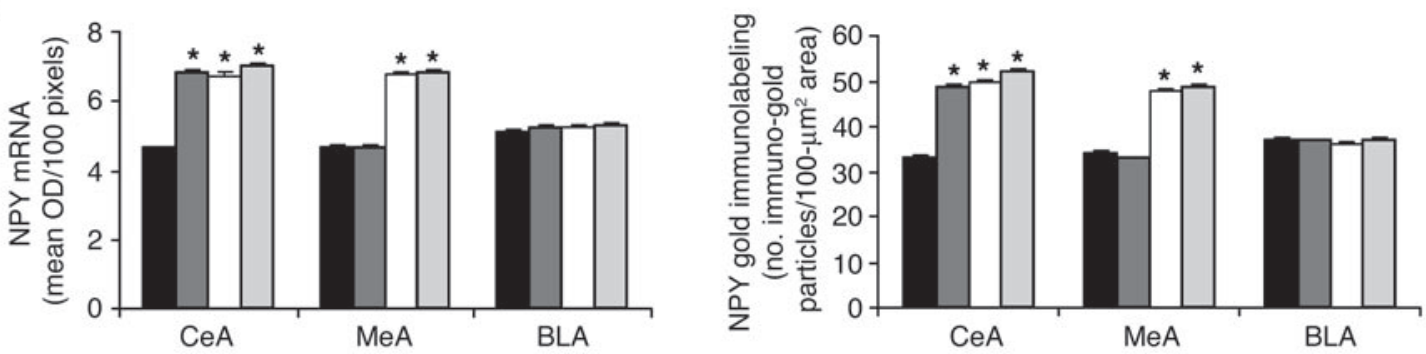

\section{Figure 8}

PKA activator infusion into the CeA during ethanol intake and NPY levels in the amygdala of $P$ rats. (A) Low-magnification views of NPY mRNA expression (in situ RT-PCR; upper panels) and NPY gold immunolabeling (lower panels) in the CeA of P rats with or without PKA activator infusion during ethanol exposure. Inset shows the gold particles in a cell body at high magnification $(\times 100)$. Scale bar: $40 \mu \mathrm{m}$. (B) Effects of voluntary ethanol exposure and PKA activator infusion into the CeA on mRNA and protein levels of NPY in the CeA, MeA, and BLA structures of rats. Values represent the mean \pm SEM of $5-6$ rats in each group. ${ }^{*} P<0.001$ versus respective controls.

malization of PKA inhibitor-induced reductions in the levels of PKA-C $\alpha$, p-CREB, and NPY expression in the CeA. These results suggest that by regulating $\mathrm{PKA} \rightarrow \mathrm{CREB} \rightarrow \mathrm{NPY}$ signaling in the $\mathrm{CeA}$, one can change the phenotype of $\mathrm{P}$ and NP rats. Since PKA $\rightarrow$ $\mathrm{CREB} \rightarrow \mathrm{NPY}$ signaling in the MeA is increased by ethanol exposure in $\mathrm{P}$ rats, it is possible that CREB function in the MeA may also regulate the anxiety and alcohol-drinking behaviors of $P$ rats. Future studies will be needed to investigate this possibility. It has also been shown that PKA inhibitor infusions into the CeA, but not the BLA, of an unselected stock of rats provokes anxiety-like behaviors and promotes alcohol-drinking behavior, and drinking behaviors were attenuated by NPY or PKA activator infusions into the CeA (30). The results of this study identify a pathway that regulates NPY expression in the CeA, and this pathway may be responsible for regulating anxiety and alcohol-drinking behaviors of $\mathrm{P}$ rats (Figure 13).

In summary, these novel findings show for the first time to our knowledge that decreased CREB phosphorylation and NPY expression in the CeA may be part of a neuromechanism opera-

\section{Figure 9}

The effect of NPY infusion into the CeA on ethanol intake and anxietylike behaviors in $\mathrm{P}$ rats. Upper panel: The alcohol-drinking patterns $(7$ and $9 \%$ ethanol) and the effect of NPY infusion into the CeA (last 3 days of $9 \%$ ethanol intake) on alcohol intake in $\mathrm{P}$ rats. Values represent the mean \pm SEM of 7 rats in each group. Lower panel: The effect of NPY infusion $(0.5 \mu \mathrm{l}$ of aCSF or $0.5 \mu \mathrm{l}$ of $100 \mathrm{pmol}$ of NPY, once daily for 3 days) and alcohol consumption on open- and closed-arm activities of $P$ rats in the EPM. Values represent the mean \pm SEM of 7 rats in each group. ${ }^{\#} P<0.01,{ }^{*} P<0.001$ versus $P$ rats infused with aCSF. tive in regulating the high anxiety and excessive alcohol-drinking behaviors of $P$ rats. We also suggest that decreased CREB function in the CeA may be a common molecular mechanism for comorbidity of anxiety and alcoholism (Figure 13). This study provides evidence that CREB may regulate the anxiety and alcohol-drinking

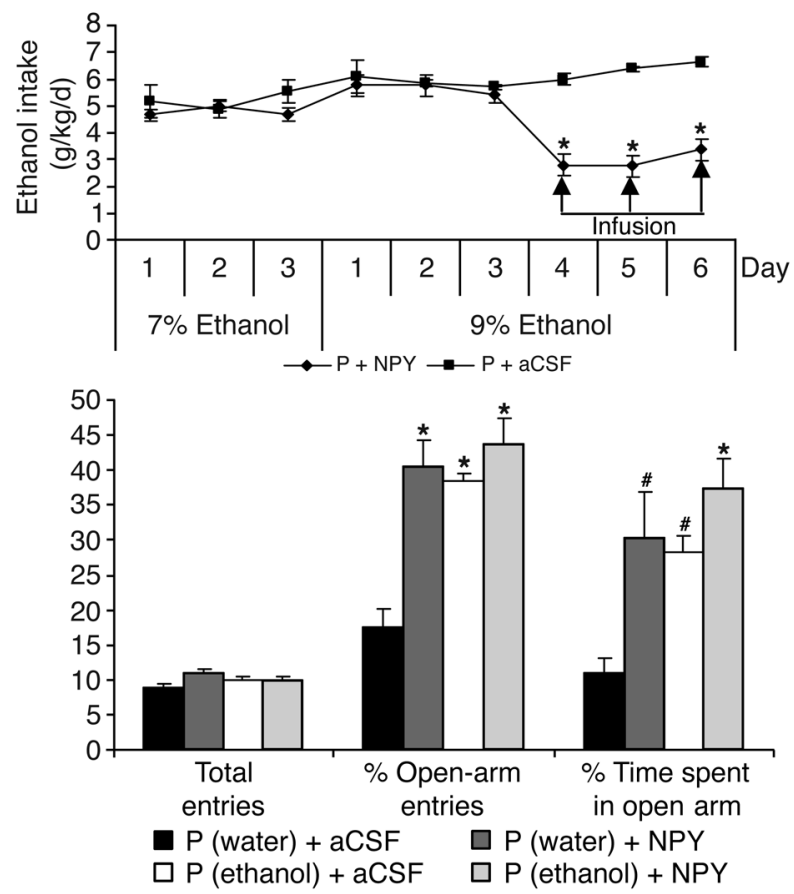



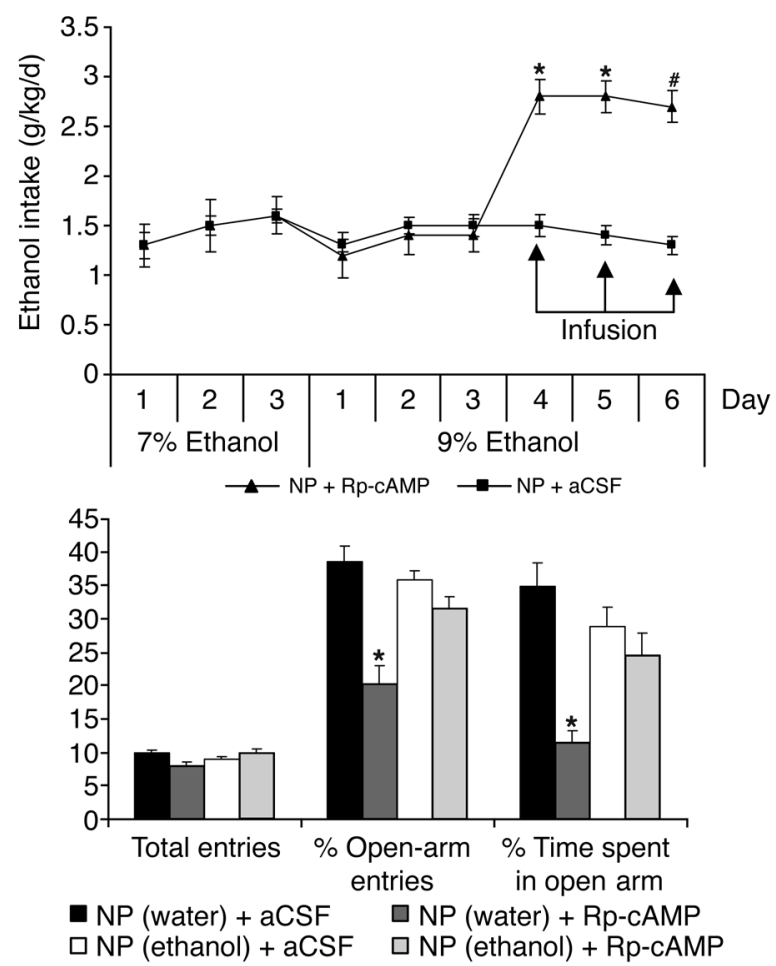

behaviors of P rats by regulating NPY expression in the CeA. Corticotropin releasing factor (CRF) is another CREB target gene, and it has previously been shown that CRF expression is lower in the CeA of P rats compared with NP rats (16). Since CRF is implicated in anxiety and alcohol-drinking behaviors $(8,58)$, it possible that CREB may regulate anxiety and alcohol-drinking behaviors of $\mathrm{P}$ rats via the CRF system. Future studies are needed to investigate the role of CRF or other CREB-related genes (27) in the neural circuitry of the CeA and MeA with the phenomenon of anxiety and alcohol preference in $\mathrm{P}$ rats or in other animal models.

\section{Methods}

\section{Baseline studies with $P$ and NP rats}

All experiments were conducted in accordance with the NIH Guidelines for Care and Use of Laboratory Animals and approved by the Institutional Animal Care Committee of University of Illinois at Chicago and Jesse Brown VA Medical Center. Alcohol-naive adult male P and NP rats (weighing about $350 \mathrm{~g}$ at the beginning of the experiment) were purchased from the Indiana Alcohol Research Center and were used in all studies. After arrival, rats were housed in a temperature- and light-controlled environment for several days. These lines of rats have been selectively bred for more than 55 generations. For baseline studies, rats were first measured for anxiety-like behaviors as described below and then immediately perfused to collect the brains for immunohistochemistry and in situ RT-PCR as described below.

Measurement of anxiety-like behaviors by the EPM test. The test procedure was the same as that previously described by us $(30,31)$. The EPM apparatus consists of 2 open arms and 2 closed arms arranged directly opposite each other and connected to a central platform. After a 5-minute habituation period, a test rat was placed on the central platform facing an open arm. The P or NP rat was observed for a 5-minute test period. The number of entries made to each type of arm (open or closed) was

\section{Figure 10}

The effect of PKA inhibitor infusion into the CeA on ethanol intake and anxiety-like behaviors in NP rats. Upper panel: The alcohol-drinking patterns (7 and $9 \%$ ethanol) and the effect of Rp-cAMP infusion into the CeA (last 3 days of $9 \%$ ethanol intake) on alcohol intake in NP rats. Values represent the mean \pm SEM of $7-8$ rats in each group. Lower panel: The effect of PKA inhibitor infusion $(0.5 \mu \mathrm{l}$ of $40 \mathrm{nmol}$ of Rp-cAMP or aCSF once daily for 3 days) and alcohol drinking on openand closed-arm activities of NP rats in the EPM. Values represent the mean \pm SEM of $7-8$ rats in each group. $\# P<0.01,{ }^{*} P<0.001$ versus NP rats infused with aCSF.

recorded. EPM test results were expressed as the mean \pm SEM of the percent of open-arm entries and the mean percent of time spent on the open arms (open-arm activity). The general activity of the each rat was measured by calculating the total number of the arm entries (open- plus closed-arm entries) in the EPM.

Gold immunolabeling of CREB, $p$-CREB, PKA, and NPY. Rats were anesthetized (using $50 \mathrm{mg} / \mathrm{kg}$ pentobarbital i.p.) after anxiety measurements were taken and then perfused intracardially with $\mathrm{n}$-saline $(100 \mathrm{ml})$ followed by $400 \mathrm{ml}$ of $4 \%$ ice-cold paraformaldehyde fixative. Brains were used for gold immunolabeling as described previously by us $(30,31,57,59)$. The antibodies for CREB, p-CREB, PKA-C $\alpha$, and NPY have been characterized previously by our laboratory $(30,31,57,59)$. The gold-immunolabeled particles of CREB, p-CREB, and PKA-C $\alpha$ were measured using an Image Analysis System (Loats Associates Inc.) connected to a light microscope that calculated the number of immuno-gold particles per $100-\mu \mathrm{m}^{2}$ area of defined brain structures (shell and core regions of NAc and CeA, MeA, and BLA). The threshold of each image was set up in such a way that areas without staining should give 0 counts. Under this condition, immuno-gold particles in the defined areas of 3 adjacent brain sections (a total of 9 fields) were counted, and then values were averaged for each rat.

Measurement of $m R N A$ levels of NPY by in situ RT-PCR. Rat brain sections were used to determine mRNA levels of NPY using in situ RT-PCR, as we previously reported $(30,31,57)$. Briefly, the procedure was as follows: brain sections were reverse transcribed and then PCR was performed with Taq DNA polymerase enzyme (Applied Biosystems) and 36-38 pmol of each NPY primer (5'-TAGGTAACAAACGAATGGGG-3' and 5'AGGATGAGATGAGATGTGGG-3') and $1 \mathrm{mM}$ of deoxyribonucleoside triphosphates, except dTTP was replaced by digoxigenin-11-dUTP. PCR conditions were as follows: 25 cycles of $94^{\circ} \mathrm{C}$ for 3 minutes, $94^{\circ} \mathrm{C}$ for 45 seconds, $60^{\circ} \mathrm{C}$ for 45 seconds, and $72^{\circ} \mathrm{C}$ for 45 seconds, followed by $72^{\circ} \mathrm{C}$ for 7 minutes. After PCR, sections were mounted on slides, and NPY-positive cell bodies were detected using alkaline phosphatase-conjugated anti-digoxigenin antibody and subsequent staining of the complex with specific substrate NBT/BCIP (Roche Molecular Biochemicals). The OD of positive cell bodies was calculated with an Image analyzer (Loats Associates Inc.). The OD of the negative brain sections was subtracted from that of the positive brain sections. The OD of positive cell bodies in the amygdaloid structures of 3 adjacent brain sections of each rat were calculated, and values were averaged for each rat. The results are represented as the mean OD per 100-pixel area.

\section{Studies related to voluntary ethanol intake and ethanol injection}

Alcohol preference was measured by the 2-bottle free choice paradigm. $\mathrm{P}$ and NP rats were placed in individual cages and habituated to drink water equally from 2 bottles. One group of $\mathrm{P}$ or NP rats had free access only to water in both bottles, the second group of $\mathrm{P}$ or NP rats were given free access to one bottle containing water and a second bottle containing ethanol diluted in water. Ethanol concentration was increased as follows: 


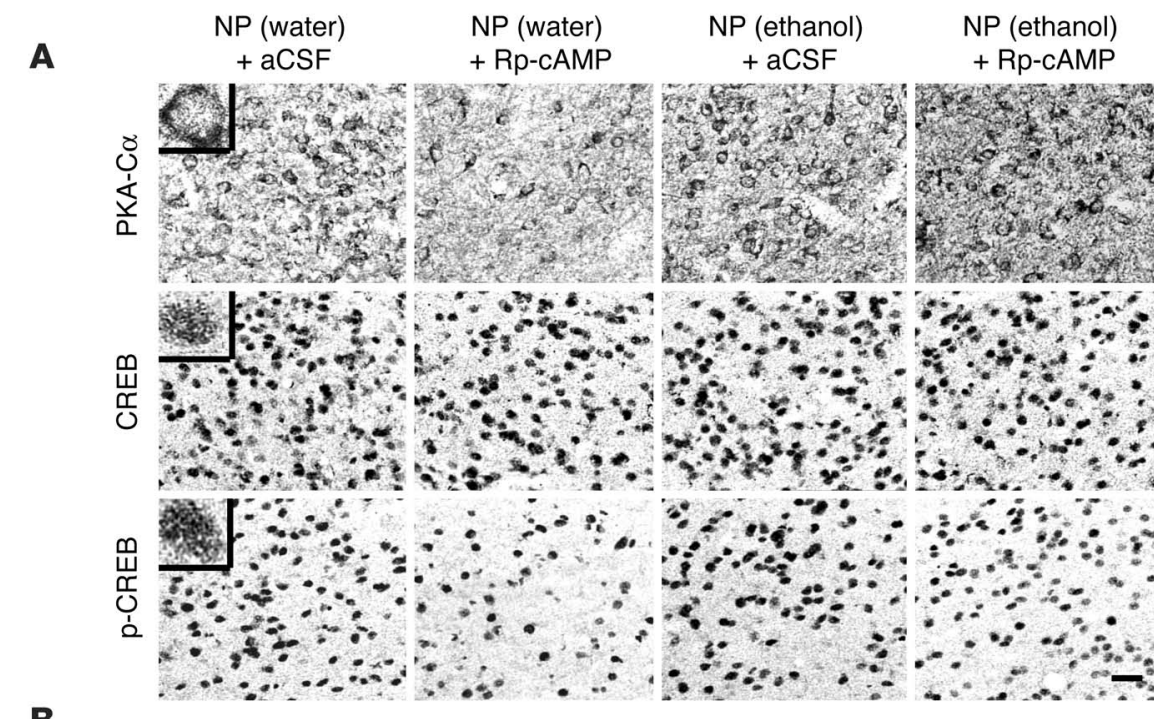

$\begin{array}{ll}\square \mathrm{NP}(\text { water })+\text { aCSF } & \square \mathrm{NP}(\text { water })+\text { Rp-cAMP } \\ \square \mathrm{NP}(\text { ethanol })+\mathrm{aCSF} & \square \mathrm{NP}(\text { ethanol })+\text { Rp-cAMP }\end{array}$
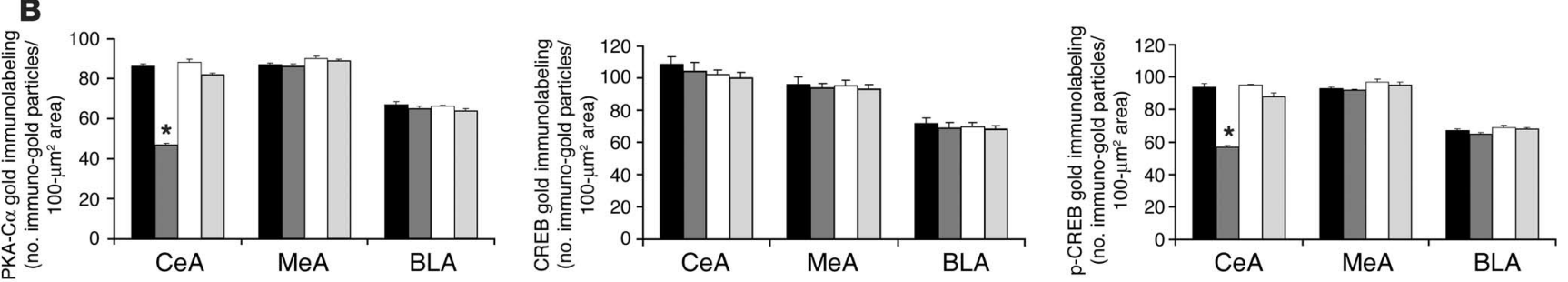

Figure 11

PKA inhibitor infusion into the CeA during ethanol intake and CREB signaling in the amygdala of NP rats. (A) Low-magnification views of PKA$\mathrm{C} \alpha, \mathrm{CREB}$, and $\mathrm{p}$-CREB gold immunolabeling in the CeA structures of NP rats infused with or without Rp-cAMP during ethanol exposure. Photomicrographs show PKA-C $\alpha$-positive cell bodies or CREB- and p-CREB-positive nuclei in the CeA of NP rats infused with aCSF or PKA inhibitor. Insets show the immuno-gold particles within a single nucleus (CREB and p-CREB) or cell body $(P K A-C \alpha)$ at high magnification $(\times 100)$. Scale bar: $40 \mu \mathrm{m}$. (B) Effect of Rp-cAMP infusion into the CeA and alcohol drinking on PKA-C $\alpha$, CREB, and p-CREB protein levels in amygdaloid structures of NP rats. Values represent the mean \pm SEM of 5 rats in each group. ${ }^{*} P<0.001$ versus NP rats infused with aCSF.

$7 \%$ ethanol for 3 days, 9\% ethanol for 3 days, and $12 \%$ ethanol for 3 days. The positions of the bottles were randomly changed every day to avoid the development of a position habit. The consumption of ethanol and water (in milliliters) was measured daily at $6 \mathrm{pm}$, at which time fresh water and ethanol solutions were provided. The ethanol consumption was calculated as $\mathrm{g} / \mathrm{kg} / \mathrm{d}$. P and NP rats were then used for anxiety measurements using the EPM.

For acute ethanol exposure, $\mathrm{P}$ and NP rats were injected i.p. with $1 \mathrm{~g} / \mathrm{kg}$ | ethanol (diluted with $\mathrm{n}$-saline) or $\mathrm{n}$-saline only. This dose of ethanol is based on the results of a previous study in P and NP rats (15). One hour after ethanol injection, anxiety-like behaviors were measured using the EPM test. We measured blood ethanol levels immediately after examining anxiety behaviors - at the time of brain collection - in P and NP rats, after voluntary ethanol intake or ethanol injection, using an Analox alcohol analyzer. Brains were processed for histochemistry. The protein levels of PKA-C $\alpha, C R E B$, and p-CREB and protein and mRNA levels of NPY were measured as described above. In all experiments, the body weight of each rat was also recorded. There were no significant differences in mean body weights between $\mathrm{P}$ and NP rats.

\section{Anxiety-like behaviors and alcohol preference after manipulation of CREB function in the CeA of $P$ and NP rats}

Implantation of cannulae. P and NP rats were anesthetized with sodium pentobarbital $(50 \mathrm{mg} / \mathrm{kg}$ i.p.) and placed in a stereotaxic apparatus. Rats were implanted bilaterally with CMA/11 guide cannulae (CMA Microdialysis) targeted $3 \mathrm{~mm}$ above the CeA. Cannulae were secured to the skull using dental cement and screws. The coordinates for CeA were: $2.5 \mathrm{~mm}$ posterior and $\pm 4.2 \mathrm{~mm}$ lateral to the bregma, and $5.1 \mathrm{~mm}$ ventral from the point of entry at the skull surface. Cannulae were covered with guided caps (CMA Microdialysis). After a recovery period of 1 week, rats were subjected to an alcohol preference test as described below.

Alcohol preference and anxiety measurements with and without CREB and NPY manipulations. Cannulated $\mathrm{P}$ and NP rats were placed in individual cages and habituated to drink water according to the 2-bottle free choice paradigm described above. Following 3 days of $7 \%$ and 3 days of $9 \%$ ethanol intake, $P$ rats were infused once (within a 2-minute period) daily for 3 days (between 5 and $6 \mathrm{pm}$ ) with $0.5 \mu \mathrm{l}$ of aCSF, $0.5 \mu \mathrm{l}$ of $80 \mathrm{nmol}$ of Sp-cAMP, or $0.5 \mu \mathrm{l}$ of $100 \mathrm{pmol}$ of NPY, and NP rats were infused with $0.5 \mu \mathrm{l}$ of aCSF or $0.5 \mu \mathrm{l}$ of $40 \mathrm{nmol}$ of Rp-cAMP, using microdialysis probes, which were attached to the automatic pump. The microdialysis probe extended $3 \mathrm{~mm}$ beyond the guide cannula into the CeA. The consumption of ethanol and water (in milliliters) was measured daily at $6 \mathrm{pm}$, at which time fresh water and ethanol solutions were provided. The ethanol intake was calculated as $\mathrm{g} / \mathrm{kg} / \mathrm{d}$.

The doses of Rp-cAMP, Sp-cAMP, and NPY were based on previous studies showing that the amounts we infused into the rat brain were able to alter alcohol and opiate withdrawal symptoms and alcohol intake (30, 57,60 ). P and NP rats were used for anxiety measurements (after 3 days of $7 \%$ and 6 days of $9 \%$ ethanol intake), and immediately after behavioral measurements were taken, brains were processed for histochemistry. The 


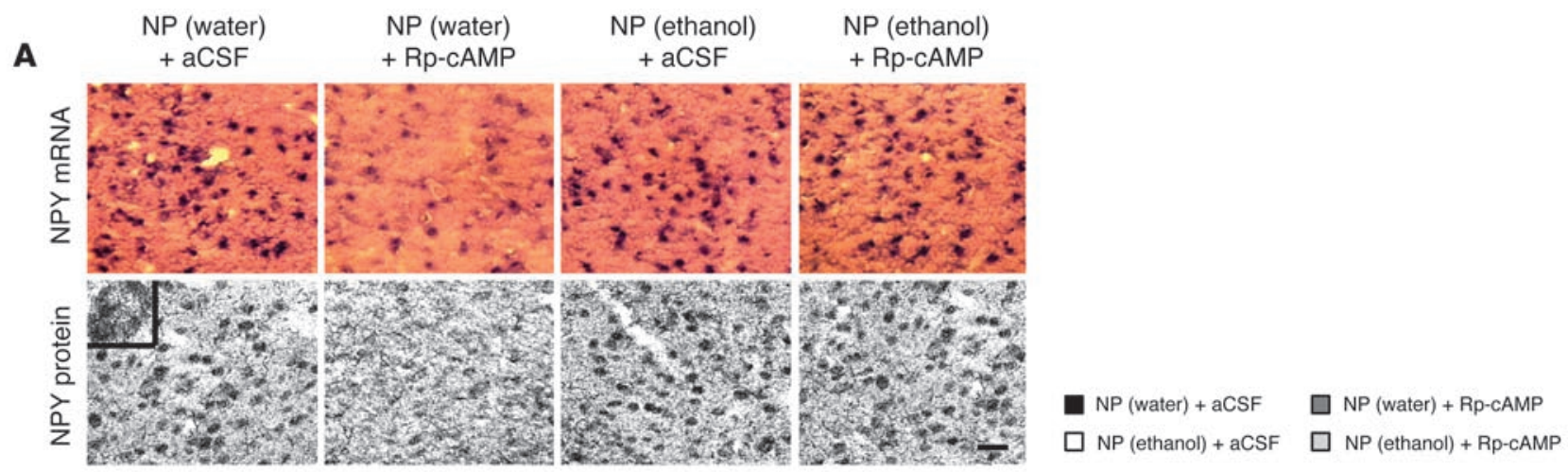

B
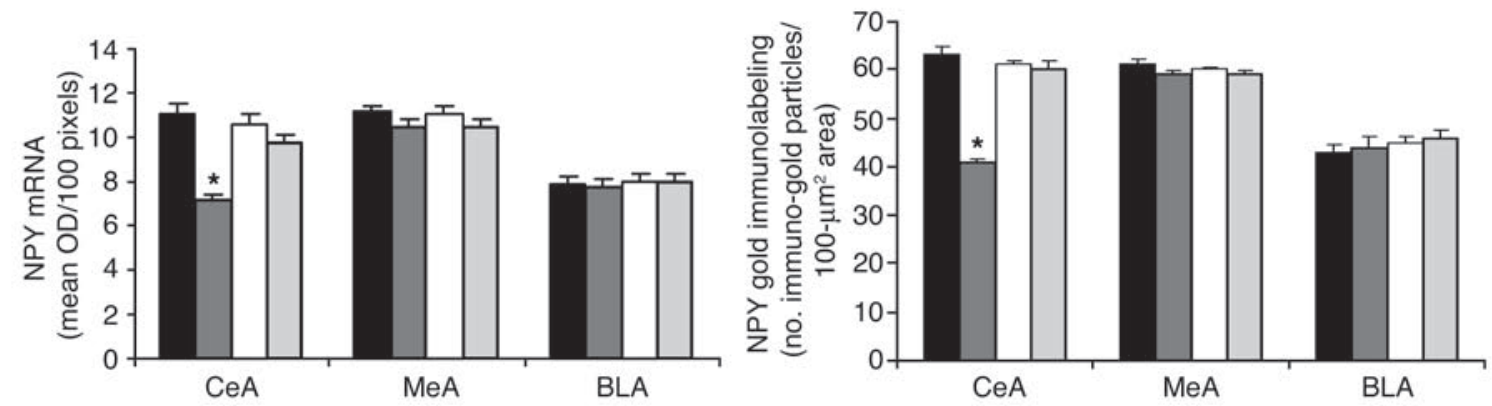

Figure 12

PKA inhibitor infusion into the CeA during ethanol intake and NPY levels in the amygdala of NP rats. (A) Low-magnification views of NPY mRNA expression (in situ RT-PCR; upper panels) and NPY gold immunolabeling (lower panels) in the CeA of NP rats with or without PKA inhibitor infusion during ethanol exposure. Inset shows the immuno-gold particles in a cell body at high magnification $(\times 100)$. Scale bar: $40 \mu \mathrm{m}$. (B) Effects of voluntary ethanol exposure and PKA inhibitor infusion into the CeA on mRNA and protein levels of NPY in the CeA, MeA, and BLA structures of NP rats. Values represent the mean \pm SEM of 5 rats in each group. ${ }^{*} P<0.001$ versus respective controls.

protein levels of PKA-C $\alpha$, CREB, and p-CREB, and protein and mRNA levels of NPY were measured after the PKA manipulations described above. All brains were also processed for Nissl staining to check the cannula positions and toxicity.

Statistics. The comparisons between 2 groups were performed by 2 -tailed Student's $t$ test. Differences among several groups were analyzed by 1 -way ANOVA followed by post hoc comparisons among groups by Tukey's test.

\section{Acknowledgments}

This study was supported by grants from the National Institute on Alcohol Abuse and Alcoholism (AA13341 and AA10005; to S.C. Pandey) and the Department of Veterans Affairs (Merit

\section{Figure 13}

Molecular mechanisms in the neural circuitry of the CeA of $\mathrm{P}$ rats for genetic predisposition to anxiety and alcohol-drinking behaviors. The data collected in the present study suggest that decreased function of CREB (within the CREB $\rightarrow$ p-CREB $\rightarrow$ NPY system) in CeA neurocircuitry may be responsible for high anxiety levels and excessive alcohol-drinking behaviors of $P$ rats. Thus, decreased CREB, p-CREB, and NPY levels represent a pre-existing genetic condition for anxiety and alcoholism. The ethanol exposure (blue arrows) causes an increase in active PKA and CREB phosphorylation and thereby increases NPY expression and attenuates anxiety behavior. PKA activator has the ability to mimic the action of alcohol on PKA and CREB phosphorylation and NPY expression in the $\mathrm{CeA}$ of $\mathrm{P}$ rats. NPY infusion into the $\mathrm{CeA}$ also attenuates anxiety and alcohol intake in $P$ rats. CREB may also alter the expression of other CREB target genes (23), whose function needs to be evaluated in future studies of anxiety and alcohol-drinking behaviors in $P$ rats. Red arrows indicate the increase or decrease of signaling protein levels.
Review Grant and Research Career Scientist; to S.C. Pandey). The Indiana Alcohol Research Center (grant AA07611) provided support for the selective breeding of $\mathrm{P}$ and NP rats.

Received for publication January 3, 2005, and accepted in revised form June 14, 2005.

Address correspondence to: Subhash C. Pandey, Department of Psychiatry, University of Illinois at Chicago, and Jesse Brown VA Medical Center, 820 South Damen Avenue (mail code 151), Chicago, Illinois 60612, USA. Phone: (312) 569-7418; Fax: (312) 569-8114; E-mail: spandey@psych.uic.edu.

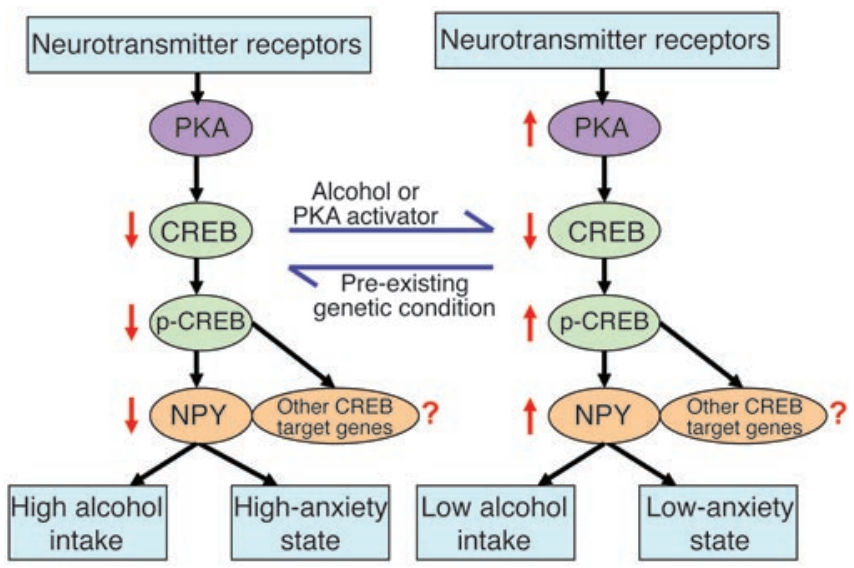


1. National Institute on Alcohol Abuse and Alcoholism. 1993. Eighth special report to the congress on alcohol and health. US Department of Health and Human Services, NIH. Bethesda, Maryland, USA.

2. Enoch, M.A. 2003. Pharmacogenomics of alcohol response and addiction. Am. J. Pharmacogenomics. 3:217-232.

3. Radel, M., and Goldman, D. 2001. Pharmacogenetics of alcohol response and alcoholism: the interplay of genes and environmental factors in thresholds for alcoholism. Drug Metab. Dispos. 29:489-494.

4. Thome, J., Gewirtz, J.C., Weijers, H.G., Wiesbeck, G.A., and Henn, F.A. 2000. Genome polymorphism and alcoholism. Pharmacogenomics. 1:63-71.

5. Cloninger, C.R. 1987. Neurogenetic adaptive mechanisms in alcoholism. Science. 236:410-416.

6. Schuckit, M.A., and Hasselbrock, V. 1994. Alcohol dependence and anxiety disorders: what is the relationship? Am. J. Psychiatry. 151:1723-1734.

7. Bibb, J.L., and Chambless, D.L. 1986. Alcohol use and abuse among diagnosed agoraphobics. Behav. Res. Ther. 24:49-58.

8. Koob, G.F. 2003. Alcoholism: allostasis and beyond. Alcohol. Clin. Exp. Res. 27:232-243.

9. Novak, A., Burgess, E.S., Clark, M., Zvolensky, M.J., and Brown, R.A. 2003. Anxiety sensitivity, selfreported motives for alcohol and nicotine use, and level of consumption. J. Anxiety Disord. 17:165-180.

10. Pandey, S.C. 2003. Anxiety and alcohol abuse disorders: a common role for CREB and its target, the neuropeptide Y gene [review]. Trends Pharmacol. Sci. 24:456-460.

11. Li, T.-K., Lumeng, L., McBride, W.J., and Murphy, J.M. 1987. Alcoholism: is it a model for the study of disorders of mood and consumatory behavior? Ann. N. Y. Acad. Sci. 499:239-249.

12. Li, T.-K., Lumeng, L., and Doolittle, D.P. 1993. Selective breeding for alcohol preference and associated responses. Behav. Genet. 23:163-170.

13. Murphy, J.M., et al. 2002. Phenotypic and genotypic characterization of the Indiana University rat lines selectively bred for high and low alcohol preference. Behav. Genet. 32:363-388.

14. McBride, W.J., and Li, T.-K. 1998. Animal models of alcoholism: neurobiology of high alcohol drinking behaviors in rodents. Crit. Rev. Neurobiol. 12:339-369.

15. Stewart, R.B., Gatto G.J., Lumeng L., Li, T.-K., and Murphy, J.M. 1993. Comparison of alcohol-preferring $(\mathrm{P})$ and non-preferring $(\mathrm{NP})$ rats on tests of anxiety and for the anxiolytic effects of ethanol. Alcohol. 10:1-10.

16. Hwang, B.H., Stewart, R., Zhang, J.-K., Lumeng, L., and $\mathrm{Li}, \mathrm{T}$.-K. 2004. Corticotropin-releasing factor gene expression is down-regulated in the central nucleus of the amygdala of alcohol-preferring rats which exhibit high anxiety: a comparison between rat lines selectively bred for high and low preference. Brain Res. 1026:143-150.

17. Mckinzie, D.L., et al. 2000. Acoustic startle and fear-potentiated startle in alcohol-preferring $(\mathrm{P})$ and -nonpreferring (NP) lines of rats. Pharmacol. Biochem. Behav. 65:691-696.

18. Viglinskaya, I.V., et al. 1995. To drink or not drink: tests of anxiety and immobility in alcohol-preferring and alcohol-nonpreferring rat strains. Physiol. Behav. 57:937-941.

19. Waller, M.B., Murphy, J.M., McBride, W.J., Lumeng, L., and Li, T.-K. 1986. Effect of low dose ethanol on spontaneous motor activity in alcohol-preferring lines of rats. Pharmacol. Biochem. Behav. 24:617-623.

20. Murphy, J.M., Gatto, G.J., McBride, W.J., Lumeng, L., and Li, T.-K. 1989. Operant responding for oral ethanol in the alcohol-preferring $\mathrm{P}$ and alcohol non-preferring NP lines of rats. Alcohol. 6:127-131.

21. Waller, M.B., McBride, W.J., Lumeng, L., and Li, T.-K. 1982. Induction of dependence on ethanol by free-choice drinking in alcohol preferring rats. Pharmacol. Biochem. Behav. 16:501-507.
22. Silva, A.J., Kogan, J.H., Frankland, P.W., and Kida, S. 1998. CREB and memory. Annu. Rev. Neurosci. 21:127-148.

23. Soderling, T.R. 1999. The $\mathrm{Ca}^{2+}$-calmodulin-dependent protein kinase cascade. Trends Biochem. Sci. 24:232-236.

24. Impey, S., Obrietan, K., and Storm, D.R. 1999. Making new connections: role of ERK/MAP kinase signaling in neuronal plasticity. Neuron. 23:11-14.

25. Lonze, B.E., and Ginty, D.D. 2002. Function and regulation of CREB family transcription factors in the nervous system. Neuron. 35:605-623.

26. Mayr, B., and Montminy, M. 2001. Transcriptional regulation by the phosphorylation-dependent factor CREB. Nat. Rev. Mol. Cell Biol. 2:599-609.

27. McClung, C.A., and Nestler, E.J. 2003. Regulation of gene expression and cocaine reward by CREB and Delta FosB. Nat. Neurosci. 6:1208-1215.

28. Yang, X., Horn, K., Baraban, J.M., and Wand, G.S. 1998. Chronic ethanol administration decreases phosphorylation of cyclic AMP-response element binding protein in granule cells of rat cerebellum. J. Neurochem. 70:224-232.

29. Pandey, S.C. 2004. The gene transcription factor cyclic AMP-responsive element binding protein: role in positive and negative affective states of alcohol addiction. Pharmacol. Ther. 104:47-58.

30. Pandey, S.C., Roy, A., and Zhang, H. 2003. The decreased phosphorylation of cyclic adenosine monophosphate (cAMP) response element binding (CREB) protein in the central amygdala acts as a molecular substrate for anxiety related to ethanol withdrawal in rats. Alcohol. Clin. Exp. Res. 27:396-409.

31. Pandey, S.C., Roy, A., Zhang, H., and Xu, T. 2004. Partial deletion of the CREB gene promotes alcohol-drinking behaviors. J. Neurosci. 24:5022-5030.

32. Bison, S., and Crews, F. 2003. Alcohol withdrawal increases neuropeptide Y immunoreactivity in rat brain. Alcohol. Clin. Exp. Res. 27:1173-1183.

33. Li, J., Li, Y.-H., and Yuan, X.-R. 2003. Changes of phosphorylation of cAMP response element binding protein in rat nucleus accumbens after chronic ethanol intake: naloxone reversal. Acta Pharmacol. Sin. 24:930-936.

34. Pandey, S.C., Mittal, N., Lumeng, L., and Li, T.-K. 1999. Involvement of the cyclic AMP-responsive element binding protein gene transcription factor in genetic preference for alcohol drinking behavior. Alcohol. Clin. Exp. Res. 23:1425-1434.

35. Chance, W.T., Sheriff, S., Peng, F., and Balasubramaniam, A. 2000. Antagonism of NPY-induced feeding by pretreatment with cAMP response element binding protein antisense oligonucleotide. Neuropeptides. 34:167-172.

36. Heilig, M., et al. 1993. Anxiolytic-like action of neuropeptide Y: mediation by Y1 receptor in amygdala and dissociation from food intake effects. Neuropsychopharmacology. 8:357-363.

37. Heilig, M. 2004. The NPY system in stress, anxiety and depression [review]. Neuropeptides. 38:213-224.

38. Palmiter, R.D., Erickson, J.C., Hollopeter, G., Baraban, S.C., and Schwartz, M.W. 1998. Life without neuropeptide Y [review]. Recent Prog. Horm. Res. 53:163-199.

39. Thiele, T.E., Marsh, D.J., Ste Marie, L., Bersntein, I.L., and Palmiter, R.D. 1998. Ethanol consumption and resistance are inversely related to neuropeptide Y levels. Nature. 396:366-369.

40. Hwang, B.H., Zhang, J.-K., Ehlers, C.L., Lumeng, L., and Li, T.-K. 1999. Innate differences of neuropeptide Y (NPY) in hypothalamic nuclei and central nucleus of the amygdala between selectively bred rats with high and low alcohol preference. Alcohol. Clin. Exp. Res. 23:1023-1030

41. Suzuki, R., Lumeng, L., McBride, W.J., Li, T.-K., and Hwang, B.H. 2004. Reduced neuropeptide Y mRNA expression in the central nucleus of amygdala of alcohol preferring $(\mathrm{P})$ rats: its potential involve- ment in alcohol preference and anxiety. Brain Res. 1014:251-254.

42. McBride, W.J. 2002. Central nucleus of the amygdala and the effects of alcohol and alcohol-drinking behaviors in rodents. Pharmacol. Biochem. Behav. 71:509-515.

43. Koob, G.F. 2003. Neuroadaptive mechanisms of addiction: studies on the extended amygdala. Eur. Neuropsychopharmacol. 13:442-452.

44. Walker, D.L., Toufexis, D.J., and Davis, M. 2003. Role of the bed nucleus of the stria terminalis versus amygdala in fear, stress, and anxiety. Eur. J. Pharmacol. 463:199-216.

45. Josselyn, S.A., et al. 2001. Long-term memory is facilitated by cAMP response element-binding protein overexpression in the amygdala. J. Neurosci. 21:2404-2412.

46. Nestler, E.J. 2001. Molecular basis of long-term plasticity underlying addiction. Nat. Rev. Neurosci. 2:119-128.

47. Barco, A., Pittenger, C., and Kandel, E.R. 2003. CREB, memory enhancement and the treatment of memory disorders: promises, pitfalls and prospects. Expert Opin. Ther. Targets. 7:101-114.

48. Cappell, H., and Herman, C.P. 1972. Alcohol and tension reduction. A review [review]. Q. J. Stud. Alcohol. 33:33-64.

49. Spanagel, R., et al. 1995. Anxiety: a potential predictor of vulnerability to the initiation of ethanol self-administration in rats. Psychopharmacology. 122:369-373.

50. Wilson, G.T. 1988. Alcohol and anxiety. Behav. Res. Ther. 26:369-381.

51. Asher, O., Cunningham, T.D., Yao, L., Gordon, A.S., and Diamond, I. 2002. Ethanol stimulates cAMPresponsive element (CRE)- mediated transcription via CRE-binding protein and cAMP-dependent protein kinase. J. Pharmacol. Exp. Ther. 301:66-70.

52. Constantinescu, A., Gordon, A.S., and Diamond, I. 2002. cAMP-dependent protein kinase types I and II differentially regulate cAMP response element-mediated gene expression: implications for neuronal responses to ethanol. J. Biol. Chem. 277:18810-18816.

53. Badia-Elder, N.E., et al. 2001. Effect of neuropeptide Y (NPY) on oral ethanol intake in Wistar, alcohol-preferring, and -nonpreferring (NP) rats. Alcohol Clin. Exp. Res. 25:386-390.

54. Slawecki, C.J., Betancourt, M., Walpole, T., and Ehlers, C.L. 2000. Increases in sucrose consumption, but not ethanol consumption, following ICV NPY administration. Pharmacol. Biochem. Behav. 66:591-594.

55. Valverde, O., et al. 2004. Modulation of anxiety-like behaviors and morphine dependence in CREB-deficient mice. Neuropsychopharmacology. 29:1122-1133.

56. Barrot, M., et al. 2002. CREB activity in the nucleus accumbens shell controls gating of behavioral responses to emotional stimuli. Proc. Natl. Acad. Sci. U. S. A. 99:11435-11440.

57. Zhang, H., and Pandey, S.C. 2003. Effects of PKA modulation on the expression of neuropeptide $\mathrm{Y}$ in rat amygdaloid structures during ethanol withdrawal. Peptides. 24:1397-1402

58. Olive, M.F., et al. 2003. A role for corticotropin releasing factor (CRF) in ethanol consumption, sensitivity, and reward as revealed by CRF-deficient mice. Psychopharmocology (Berl.). 165:181-187.

59. Roy, A., and Pandey, S.C. 2002. The decreased cellular expression of neuropeptide $Y$ protein in the rat brain structures during ethanol withdrawal after chronic ethanol exposure. Alcohol. Clin. Exp. Res. 26:796-803.

60. Punch, L.J., Self, D.W., Nestler, E.J., and Taylor, J.R. 1997. Opposite modulation of opiate withdrawal behaviors on microinfusion of a protein kinase A inhibitor versus activator in the locus coeruleus or periaquenductal gray. J. Neurosci. 17:8520-8527. 